\title{
Complutum
}

ISSN: 1131-6993

\section{Lo que la cerámica esconde: continuidad y cambio social a finales del Bronce y comienzos de la Edad del Hierro en el castro de las Cogotas (Cardeñosa, Ávila)}

\author{
Juan Jesús Padilla Fernández; Alberto Dorado Alejos²
}

Recibido: 8 de enero de 2016 / Aceptado: 30 de junio de 2017

Resumen. El presente trabajo expone ciertas reflexiones sobre la producción cerámica del Castro de Las Cogotas (Cardeñosa, Ávila) durante el paso de la Edad del Bronce a la Edad del Hierro. A través de la cerámica, entendida ésta como un elemento revelador para la interpretación de comunidades pasadas, y por tanto, capaz de suplir las carencias presumibles del registro, ha sido posible identificar una relación estrecha entre los conjuntos de Cogotas I y Cogotas II. La identificación manifiesta de permanencias y cambios tecnológicos adoptados en torno al savoir faire cerámico, evidencia, entre otras cosas, la ausencia en el yacimiento abulense de facies intermedias y la coexistencia en el modo de hacer de modelos de aprendizaje verticales y horizontales. Se trata, sin duda, de pruebas fehacientes de la complejidad ontológica meseteña dentro de un periodo considerado habitualmente de tránsito.

Palabras clave: tecnología cerámica; alteridad; hibridación; Bronce Final; I Edad del Hierro.

\section{[en] What Ceramics hide: Continuity and Social Change in the Late Bronze Age and Early Iron Age in the Las Cogotas Hillfort (Cardeñosa, Ávila)}

\begin{abstract}
This paper presents some reflections on ceramic production carried out in the Las Cogotas hillfort (Cardeñosa, Ávila) during the passage from the Bronze Age to the Iron Age. It has been possible to identify a close relationship between the ceramic assemblages of Cogotas I and Cogotas II using ceramics as a revealing element for the interpretation of past communities, able to supply the presumed shortcomings of the record,. The clear identification in this site of technological continuity and changes adopted in the pottery savoir faire evinces, among other things, the absence of intermediate phases and the coexistence of vertical and horizontal learning styles. The paper presents thus, a strong evidence of ontological complexity in the Meseta within a period usually considered as transitional.
\end{abstract}

Keywords: Pottery Technology; Alterity; Hybridization; Late Bronze Age; Iron Age.

Sumario. 1. Introducción. 2. Tecnología y sociedad cerámica. 3. ¿Tipología o tecnología? La cerámica de Cogotas I. 3.1. Selección, extracción y preparación de las materias primas. 3.2. Modelado. 3.3. Cocción. 4. ¿Tipología o tecnología? La cerámica de Cogotas II. 4.1. Selección, extracción y preparación de las materias primas. 4.2. Modelado. 4.3. Cocción. 5. Cogotas I vs Cogotas II: El valor de la diferencia. 6. Consideraciones finales.

Cómo citar: Padilla Fernández, J.J.; Dorado Alejos, A. (2017): Lo que la cerámica esconde: continuidad y cambio social a finales del Bronce y comienzos de la Edad del Hierro en el castro de las Cogotas (Cardeñosa, Ávila). Complutum, 28(1): $87-117$.

\section{Introducción}

La palabra Cogotas se encuentra íntimamente ligada a la Arqueología española. Capaz de retrotraernos a las primeras excavaciones realizadas con metodología científica en nuestro país, este vocablo fue pronto convertido en concepto con la principal premisa de justificar

\footnotetext{
Universidad Complutense de Madrid, Facultad de Geografía e Historia, Departamento de Prehistoria (España) E-mail: juanjpad@ucm.es

2 Universidad de Granada, Facultad de Filosofía y Letras, Departamento de Prehistoria y Arqueología (España)

E-mail: a.dorado.alejos@hotmail.com
} 


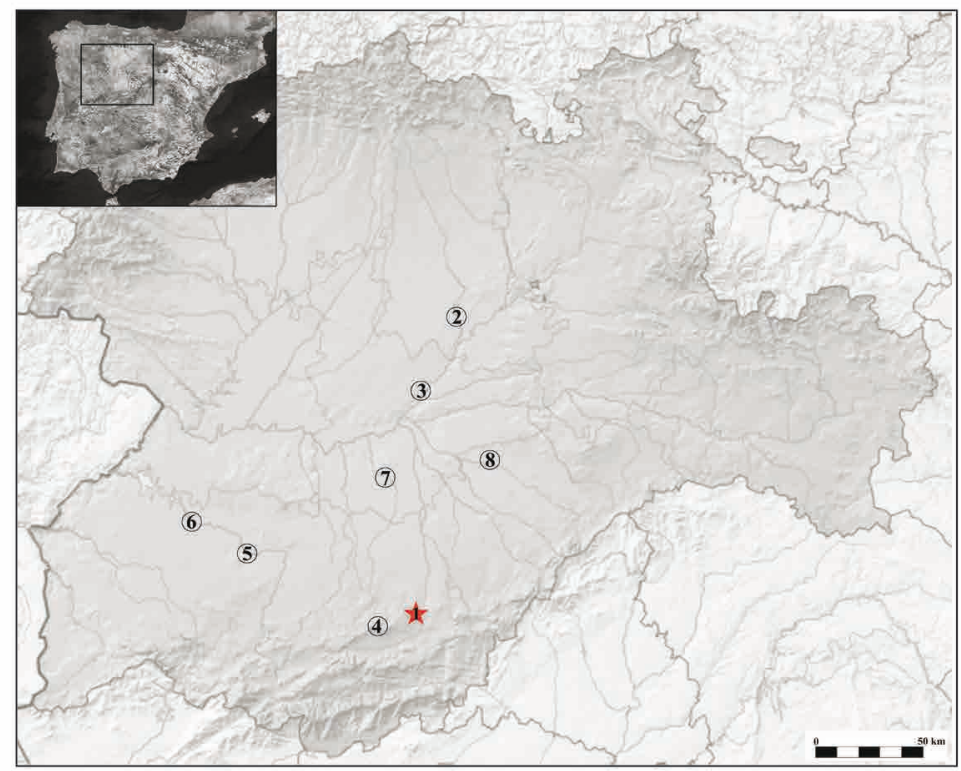

Figura 1. Emplazamiento Geográfico del sitio Arqueológico de Las Cogotas, así como del resto de yacimientos mencionados en el presente trabajo: 1) Castro de las Cogotas (Cardeñosa, Ávila); 2) Pico Castro (Dueñas, Palencia); 3) Soto de Medinilla (Valladolid); 4) Los Castillejos (Sanchorreja, Ávila);

5) Cerro de San Vicente (Salamanca); 6) Ledesma (Salamanca); 7) La Mota (Medina del Campo, Valladolid), y 8) Cuéllar (Segovia). (Autores).

materialmente la construcción decimonónica de una Historia milenaria. La configuración de construcciones temporales y la enumeración de grandes listados tipológicos acordes a ellas, propiciaron el surgimiento del término Cogotas como un fósil guía, en torno al cual explicar "pueblos" y culturas ya desaparecidas (Álvarez Sanchís 2010). Afortunadamente, el desarrollo epistemológico de la práctica arqueológica ha comenzado a dejar atrás la importancia del objeto en sí, para ajustarse a lo que éste esconde dentro de sí. De forma más frecuente, la exploración del registro aparece vinculada a la esfera de lo social, originando discursos que centran una atención capital en las personas (Ruiz Zapatero y Álvarez Sanchís 2002; Álvarez Sanchís 2008; Abarquero Moras 2012; Blanco González 2015a). No obstante, debemos ser realistas y tener conciencia de que todavía queda un largo camino por recorrer. La cerámica de Cogotas sigue siendo heredera del paradigma que la creó. Hermética y esclava de sus caracteres formales, continúa perpetuando la distinción puntual de periodos crono-culturales claves de la prehistoria ibérica como la Edad del Bronce y las Edades del Hierro I y II. Desde que Juan Cabré iniciara sus investigaciones en el castro y necrópolis de
Las Cogotas en los años 1920, ha permanecido latente la idea de que nos encontramos ante comunidades distintas e independientes que producen y usan cosas diferentes. Pero, ¿son esas cosas, y concretamente la cerámica, realmente diferentes?

Estas líneas tienen la pretensión de tratar de conocer al pasado no como un proceso lineal, gradual y progresivo, sino como un cúmulo de complejas memorias culturales dotadas de carácter propio; memorias que residen en la materialidad y que tradicionalmente han sido obviadas dentro de la arqueología meseteña ibérica. La presentación y lectura por María de la Encarnación Cabré de la comunicación titulada "Cerámica de Las Cogotas con grabados solares" en el IV Congreso Internacional de Arqueología, celebrado en Barcelona en 1929 (Cabré Aguiló 1930: 22), marcó el inicio de una historiografía científica basada en la observación de los conjuntos cerámicos de Cogotas como indicadores de etapas. Supeditada desde entonces a dilucidar una sucesión continuada de acontecimientos, los interrogantes sobre acerca de cómo fueron realizados, quien se encargó de su manufactura y dónde, o por y para qué se usaron, han sido relegados a un segundo plano. 
Con la finalidad de hablar sobre algo más que de "grabados solares" múltiples, proponemos aquí un cambio de perspectiva que otorga énfasis a lo tecnológico. El desgranamiento y conocimiento pormenorizado de la cadena técnica operativa cerámica ayuda a descubrir mensajes repletos de significado social (Lemmonier 2012). También puede contribuir a plantear aspectos interesantes que permitan cuestionar, o bien reforzar, determinadas consideraciones sobre un periodo, el de finales del Bronce y comienzos de la Edad del Hierro, que ha sido calificado como oscuro y de cambio en todos los sentidos (Esparza Arroyo y Blanco González 2008).

¿Por qué escoger el sitio de Las Cogotas? (Fig. 1) A pesar de la diversidad de hipótesis que giran en torno a la posibilidad de su ocupación en el tránsito del horizonte de Cogotas I a Cogotas II (Blanco González 2010a), dispone innegablemente de un importante registro material (Álvarez Sanchís 1999: 75-6; Barril 2005: 74-5) atribuido a la fase circunscrita entre los ss. IX y VII a.C. El yacimiento de Las Cogotas, repleto de vestigios cerámicos, ofrece la alternativa de llevar a cabo investigaciones con un perfil tanto diacrónico como sincrónico, acerca de las tecnologías empleadas para fabricar recipientes hechos en barro hace más de 2.000 años. Siendo conscientes del sesgo informativo con el que contamos, precisamente por carecer mayoritariamente de contextos precisos excavados, este trabajo articula su discurso en un total de 50 fragmentos de piezas cerámicas (15 adscritas a Cogotas I y las 35 restantes atribuidas a Cogotas II), ligadas al asentamiento y conservadas en los fondos del Museo Arqueológico Nacional. Su selección, fundamentada en el reconocimiento de ciertos rasgos y particularidades técnicas específicas, pretende profundizar en si hubo o no cambios en la condiciones de vida de aquellas gentes, y si fue así, tratar de explicarlas. Al mismo tiempo, este trabajo aspira a vigorizar la comprensión del enclave arqueológico de Las Cogotas como un hito significativo para el entendimiento de un marco de tiempo breve, pero repleto de lagunas.

\section{Tecnología y sociedad cerámica}

Numerosos estudios etnoarqueológicos (Livingston 2007; Gosselain 2011; Pikirayi y Lindahl 2013) han demostrado que la cerámi- ca es más que un objeto que sirve para contener líquidos o almacenar productos. Estrechamente ligada a las gentes que la generan, ésta se constituye como una fuente importante de información social (Hodder 2012). Entendemos que las actuales perspectivas teóricas desarrolladas en el seno de nuestra disciplina está permitiendo la aprehensión de ciertos conocimientos que nos llevan a una mejor comprensión de los rasgos sociales y simbólicos (Costin 2000; González Ruibal 2006). Es sin duda, una apreciación esperanzadora para todos los que trabajamos con restos arqueológicos, dada la parquedad de información que a menudo podemos extraer del orden contextual. Pero ¿cómo lo hacemos? Lógicamente debemos cambiar de enfoque.

Más allá de las características puramente formales, que pueden brindar datos útiles, el repertorio cerámico necesita ser abordado desde una perspectiva tecnológica global, que documente la integridad de las etapas relacionadas con el proceso de producción. El término de Cadena Operativa, entendido como el compendio de procedimientos desarrollados desde el momento de obtención de la materia prima hasta la consecución del producto final (Balfet 1975: 52; Creswell 1976: 13), no sólo facilita una panorámica al completo de cada una de las fases implicadas, sino que también sitúa en una misma vertiente lo físico con lo puramente inmaterial; el elemento cerámico con las circunstancias sociales y demandas ideológicas que lo determinan (Lemonnier 1986, 1993). El uso del concepto de Cadena Operativa se entiende como un eje que conecta simultáneamente el trabajo técnico con dinámicas socio-económicas (Roux 2009), ideológicas y espaciales (Dietler y Herbich 1998). En definitiva, es una herramienta que une tecnología y sociedad.

La construcción y posterior comparación sistemática de varias Cadenas Operativas generalmente pone de manifiesto la certeza de cambios o similitudes, que de igual forma afectan a los agentes sociales que participan en su desarrollo (Giddens 2003). Por tanto, la ruptura o continuidad de determinadas estructuras significaría el mantenimiento, o no, de percepciones concretas de la realidad. Los sujetos, en nuestro caso 1@s alfarer@s, colaboran activamente en la afirmación del paisaje colectivo al que pertenecen (Dobres 2010). Desde una perspectiva metodológica, cobran gran importancia las muestras que facilitan la 
comprensión del savoir faire cerámico y los procesos de aprendizaje que contribuyen a su adquisición (Van der Leeuw 1993; Gosselain 2002). La predilección, ya sea ésta voluntaria o involuntaria, por un desarrollo cognitivo explícito (García Roselló y Calvo 2013) ayuda a fortalecer el sentimiento de pertenencia a un orden común, apuntala el vínculo con una identidad específica y define lo extraño como un reflejo de la imagen del "otro" (Hernando Gonzalo 2015a). Los recipientes cerámicos arqueológicos atesoran tradiciones y reglas de comportamiento específicas de sociedades pretéritas. Acumulan en esencia evidencias privilegiadas que pueden suscitar la edificación de rutas académicas alternativas que acaben con explicaciones lineales $-\mathrm{y}$ a veces demasiado banales-, articuladas mayoritariamente sobre planteamientos actualistas y occidentales.

Nuestro marco de actuación a seguir en estas líneas quiere regirse exactamente por estos principios básicos. Con la condición primordial de teorizar sobre estrategias productivas (García Roselló 2009: 125), es decir, el modo de actuar de los grupos humanos adscritos a los tipos cerámicos de Cogotas I y Cogotas II en lo que a fabricación cerámica se refiere, planificamos un análisis técnico centrado en tres criterios elementales: 1) la descripción ordenada y exhaustiva del ciclo cerámico; 2) la definición detallada de cada uno de los gestos y prácticas empleadas durante el proceso de manufactura, y; 3) el grado de suficiencia tecnológica cerámica constatado hasta ahora para las sociedades del Bronce Final y los primeros compases de la Edad del Hierro.

Los dos apartados que siguen a continuación ensayan la recomposición de las cadenas operativas de ambos horizontes, concediendo una atención individualizada a tres grandes fases: 1) la selección, extracción y preparación de las materias primas; 2) el modelado; y 3) la cocción (Livingstone 2007; García Roselló y Calvo Trias 2013). Para ello, se ha efectuado un examen categórico de perfil macroscópico, reforzado con el visionado de lupa binocular para refutar patrones y marcas difíciles de percibir a simple vista. La intención no es otra que la de ser capaces de desgranar de manera individualizada las mecánicas tecnológicas internas ejecutadas por1@s artesan@s del castro de Las Cogotas. Si logramos acercarnos con precisión a sus conocimientos técnicos, indirectamente estaremos llamando a las puertas del primer milenio a.n.e.

\section{3. ¿Tipología o tecnología? La cerámica de Cogotas I}

Hablar de la Edad del Bronce en la esfera meseteña de la Península Ibérica significa hablar de la Cultura de Cogotas I. Desde que fue acuñada con el nombre de Cogotas en base al hallazgo en este yacimiento abulense de cantidades abundantes de cerámica adscritas a dicho periodo cronológico (Bosch Gimpera 1942, 1944), la historiografía ha tendido a considerarla como un horizonte cultural uniforme en el que las diferencias son difíciles de atisbar. Quizás, por la carencia de una información arqueológica homogénea y completa respecto a otros elementos culturales como zonas de hábitat o necrópolis, la cerámica de tipo Cogotas I ha vertebrado sistemáticamente la práctica totalidad de los estudios relacionados con esta cultura, y que como es lógico han prestado con carácter mayoritario una especial atención hacia aspectos finales, como el acabado y la decoración. Esta definición de técnicas y motivos ha determinado el establecimiento para Cogotas I de una secuencia cronocultural clara, caracterizada por poseer una cierta unidad cultural y circunscrita en torno a un orden geográfico considerado en ocasiones nuclear y en otras periférico (Delibes y Fernández 1986-1987; Castro et al. 1995, 1996; Almagro-Gorbea 1996; Blasco Bosqued 1997; Fernández-Posse 1998; Galán Saulnier 1998; Abarquero Moras 2005). Sin embargo, ¿son estas cerámicas el fiel reflejo de identidades comunes compartidas? Tal y como Ángel Esparza y Antonio Blanco plantean (2009), la falta de restos arqueológicos fiables continúa siendo un problema que impide apreciar con nitidez el porqué de las cerámicas asociadas al estilo de Cogotas I.

Ante las insuficiencias del registro disponible, nuestra investigación debe comenzar abordando cómo se elaboraron las piezas. De este modo, distintas formas de producción alfarera, definidas por variantes iconográficas y decorativas, así como destrezas tecnológicas, nos remiten a territorios culturales concretos. Si bien el objetivo que guía este trabajo no busca responder a la suma de interrogantes que giran alrededor del significado de la cerámica de Cogotas I, sí aspira a ser un buen punto de partida para consolidar la importancia de rastrear sus estrategias alfareras. 


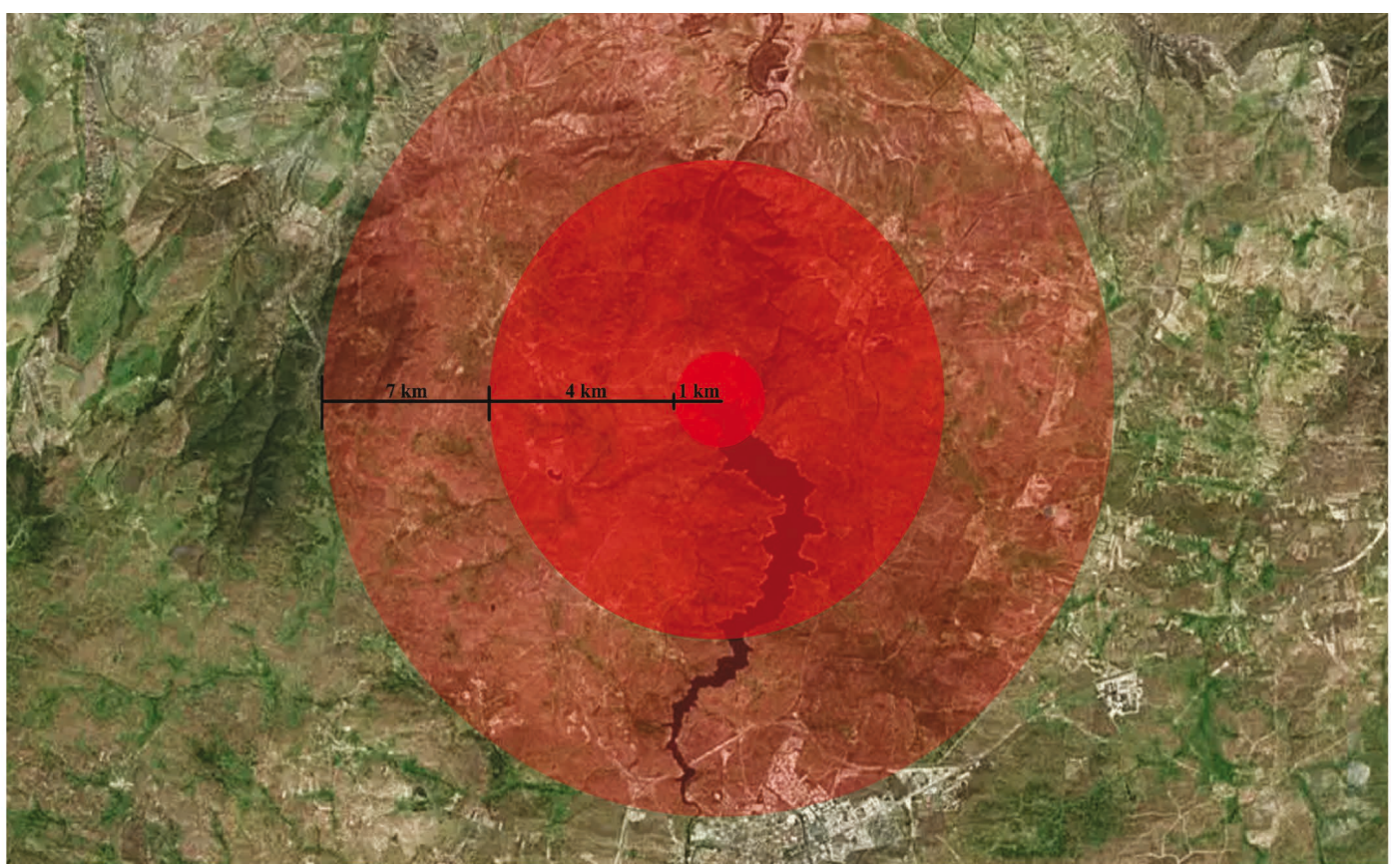

Figura 2. Mapa de Área de Captación de Recursos fijada para el yacimiento arqueológico de Cogotas. (Autores).

\subsection{Selección, extracción y preparación de las materias primas}

La arcilla como material centra la totalidad del proceso productivo cerámico. El tamaño de sus partículas y las características de los minerales que la generan como compuesto, le otorgan propiedades óptimas que la convierten en esencial para poder modelar y confeccionar elementos de naturaleza cerámica (Orton et al. 1997: 135). Asimismo, y en conexión directa con la selección de bloques arcillosos, la manufactura cerámica exige además el acopio de pigmentos y otros recursos líticos y óseos, que junto al agua y la madera, son vitales para conseguir la ductilidad apropiada, poder aplicar decoraciones y tratamientos de superficie específicos y propiciar transformaciones fisicoquímicas que conviertan un cuerpo flexible y plástico en un ente sólido y firme (Albero 2015).

La puesta en práctica del modelo Threshold Model for Ceramic Resources (Arnold 2006), ha permitido establecer interpretaciones interesantes sobre el ámbito geográfico vinculado al aprovisionamiento de materias primas y las técnicas de extracción empleadas para tal fin. La composición mineralógica que se observa en las matrices cerámicas de Cogotas I descubiertas en el asentamiento homónimo, respon- de a la explotación de un conjunto de áreas de captación de arcilla próximas entre sí y cercanas al yacimiento. La forma esférica de las especies inorgánicas más abundantes, cuarzos y micas moscovíticas, nos lleva a suponer su localización original en ámbitos de alto grado erosivo, pudiendo relacionarse posiblemente con los entornos del río Adaja y el arroyo Rominillas. Consideramos, por tanto, y a pesar de los problemas que implica por la imposibilidad de identificar la intencionalidad de un añadido previo, que estos clastos tuvieron que formar parte de la arcilla con la que fueron obrados los contenedores cerámicos, al no presentar aristas angulosas como fruto de un posible machacado intencional para su adición, una circunstancia que ya ha sido señalada para otras áreas de producción cerámica contemporáneas (Albero y Puerta 2011). Es de sospechar que el resto de materiales conectados con la cadena productiva fueran recolectados igualmente en un radio no superior a los 7 kilómetros de distancia. Cursos de agua y masas arbóreas cercanas serían aprovechadas, al mismo tiempo que cantos rodados y huesos fueron convertidos en herramientas (Fig. 2).

El número y propiedades de los desgrasantes cuantificados en las pastas cerámicas, indican la preparación meticulosa de las arcillas escogidas. Tal y como ha sido puesto de 


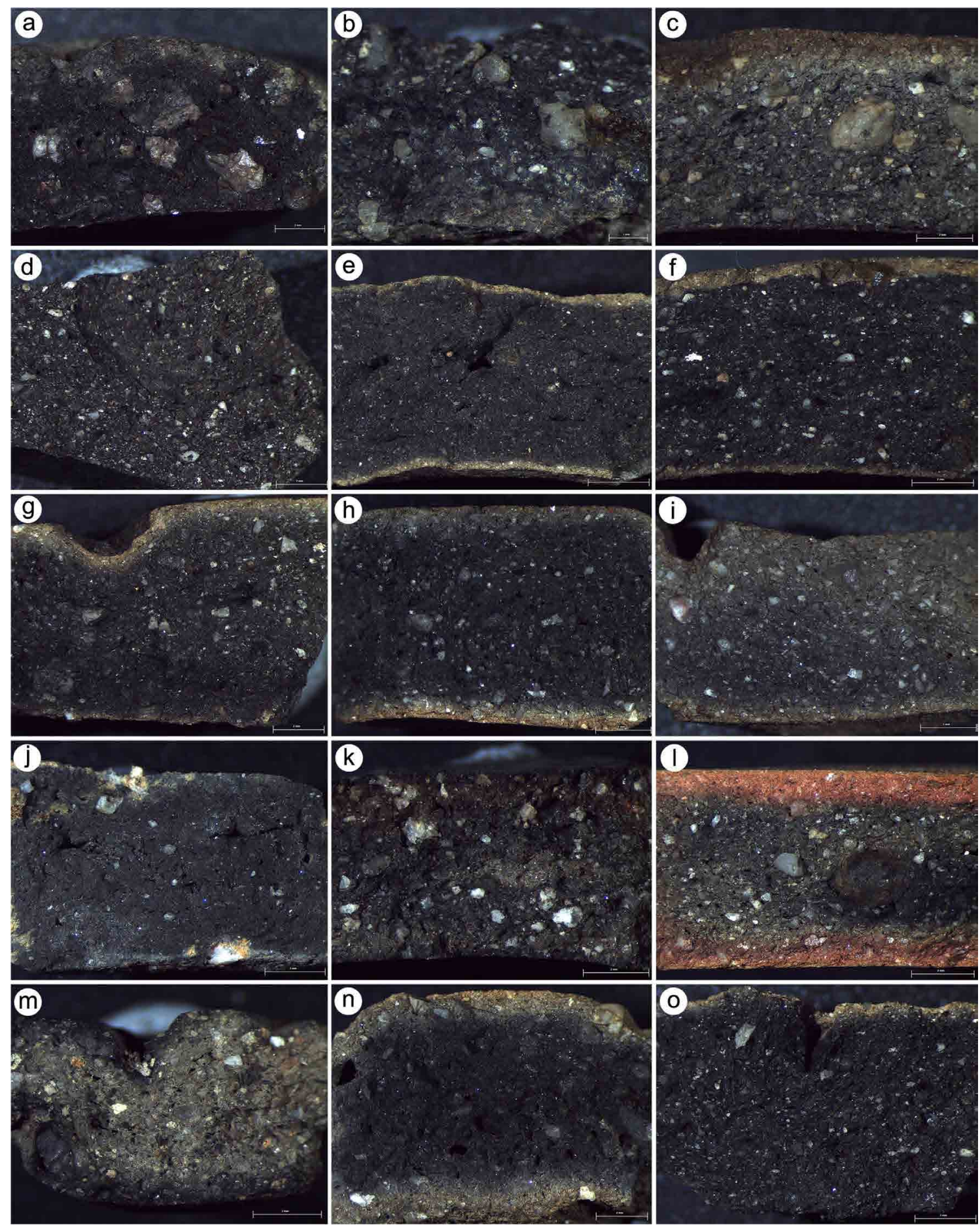

Lámina 1. Microfotografías obtenidas mediante lupa estereoscópica del conjunto de vasijas de Cogotas I procedentes del sitio de las Cogotas (Cardeñosa, Ávila), siendo: a) 1989-41-2382; b) 1989-41-2995; c) 1989-41-3122; d) 1989-41-3123; e) 1989-41-3126; f) 1989-41-3127; g) 1989-41-3163; h) 1989-41-3169; i) 1989-41-3174; j) 1989-41-3218; k) 1989-41-3570; 1) CO-1989-Vivienda 9-2; m) CO-1989-Vivienda 9-4; n) CO-1989-Vivienda 9-5; o) CO-1989-Vivienda 9-12 MAN. (Autores). 

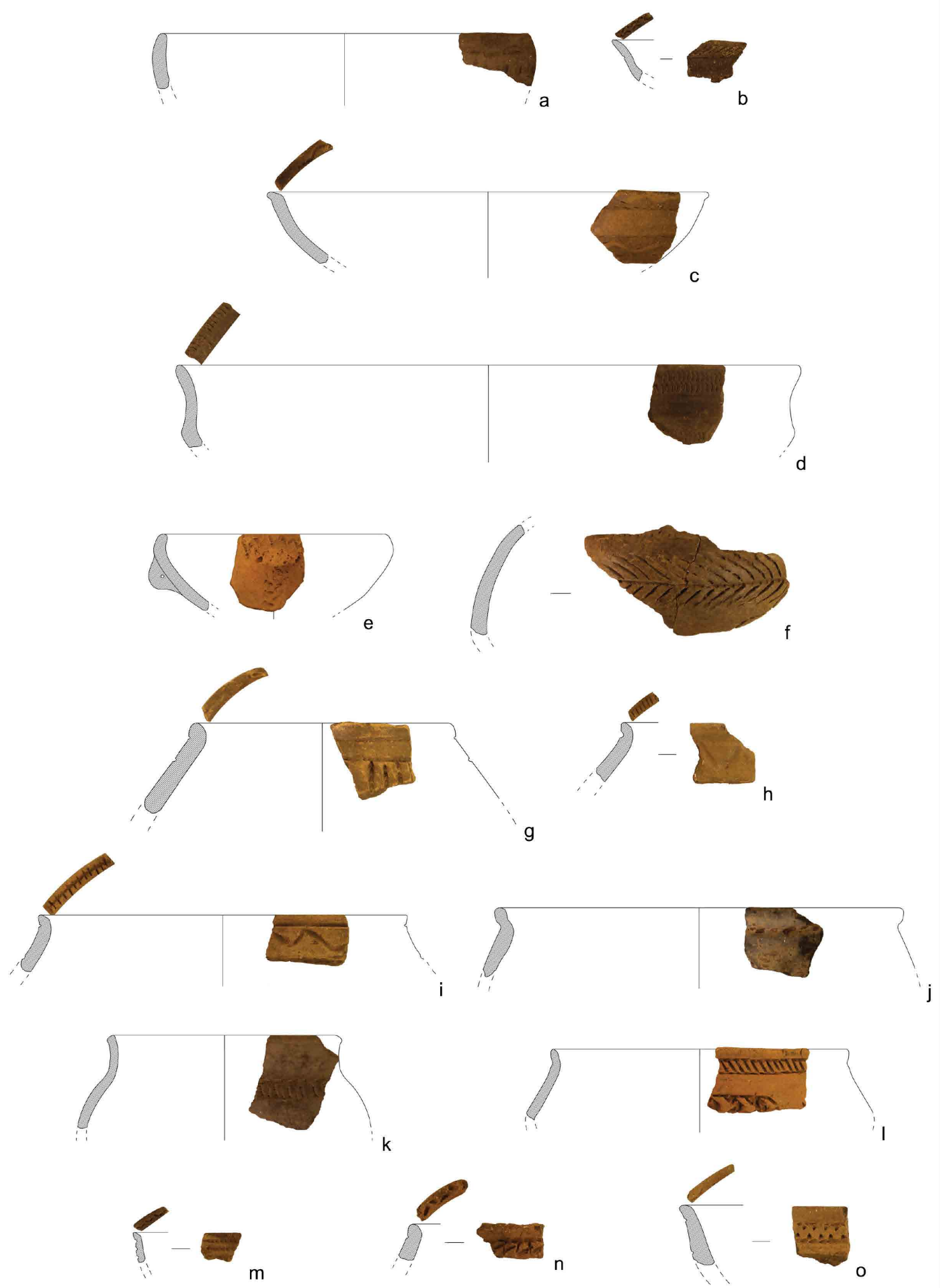

Lámina 2. Conjunto de contenedores adscritos a Cogotas I procedentes del sitio de las Cogotas (Cardeñosa, Ávila), siendo: a) 1989-41-2382; b) 1989-41-2995; c) 1989-41-3122; d) 1989-41-3123; e) 1989-41-3126; f) 1989-41-3127; g) 1989-41-3163; h) 1989-41-3169; i) 1989-41-3174; j) 1989-41-3218; k) 1989-41-3570; 1) CO-1989-Vivienda 9-2; m) CO-1989-Vivienda 9-4; n) CO-1989-Vivienda 9-5; o) CO-1989-Vivienda 9-12 MAN. (Autores). 
relieve en distintos estudios etnoarqueológicos (Druc 1996; Arnold 2000; González Ruibal 2005; Gosselain 2008; García Rosselló 2008), la limpieza o añadido de sólidos orgánicos e inorgánicos tendría lugar a través de una decantación por tamizado. Aunque realmente se trata de un proceso de difícil identificación, trazamos esta aseveración al identificar pequeñas diferencias internas en la variación de desgrasantes de las matrices cerámicas. Teniendo en cuenta las muestras seleccionadas observamos tres agrupaciones:

Grupo A: Contenedores en los que se han documentado porcentajes situados entre 2 y $10 \%$. En este primer grupo encontramos dos ollas ovoides (CO-1989-41-3163, CO-1989-Viv.9-5) y varios vasos y fuentes bitroncocónicas de variado tamaño (CO1989-41-3169, CO-1989-41-3126, CO1989-41-3218).

Grupo B: Contenedores con relaciones situadas entre el 10 y el $30 \%$. Adscritos a éste se hallan tipos de fuentes bitroncocónicas (CO-1989-41-3174, CO-1989-413127, CO-1989-Viv.9-2), una gran fuente carenada con borde curvo saliente (CO1989-41-3123), una fuente de borde vuelto (CO-1989-Viv.9-12) y un vaso con borde entrante (CO-1989-41-2382).

Grupo $C$ : Por último, un tercer grupo conformado por aquellos contenedores con medidas ligeramente superiores al $30 \%$. Entre ellos se encuentran dos fuentes con borde vuelto (CO-1989-41-3122, CO1989-Viv.9-4), una fuente con borde recto saliente (CO-1989-41-2995) y una olla ovoide (CO-1989-41-3570).

En función de la precisión en la ejecución y la malla de tamiz realizada es normal que se aprecien cantidades distintas de clastos adheridos a la masa arcillosa, siendo éstas en cualquier caso escasas si las comparamos con las proporciones halladas en estado original (Láms. 1 y 2). Simultáneamente, podemos atisbar que no hay un vínculo seguro entre diversidad de desgrasantes y tipología, descartando así la eventual transformación de pastas en consonancia con usos específicos. Un hecho que entronca perfectamente con lo ya he expuesto por Antonio Blanco (2014) en correspondencia con las fuentes de gran tamaño del yacimiento de Pico Castro (Dueñas, Palencia). La apreciación de marcas superficiales de ex- posición al fuego refuerza de manera evidente la idea de su multifuncionalidad, rechazando el manejo exclusivo de tipos fijos como servicio de mesa.

Tras la selección y consiguiente manipulación de la arcilla se procede a su pisado y amasado. Se trata de una secuencia determinante que permite la homogeneización de las pastas, de tal modo que las partículas que la conforman quedan ordenadas y distribuidas correctamente en su interior. De escasa o nula representación en el registro arqueológico, la tarea de pisar y amasar el barro ha sido asociada recurrentemente a periodos cronológicos posteriores y sobre todo a partir del mundo ibérico o helenístico, básicamente por disponer de dibujos iconográficos fiables, como por ejemplo las tablas de Pentouskophia (Coll Conesa 2000; Hasaki 2012). No obstante, la inexistencia de abigarramientos, la no observación de burbujas de aire y la no persistencia de nódulos arcillosos en las matrices de nuestra muestra de Cogotas I, parece desmentir las suposiciones tradicionales. A excepción de uno de los vasos bitroncocónicos (CO-1989-41-3126), la práctica totalidad de los fragmentos presenta una uniformidad manifiesta, poniendo de relieve la aplicación eficiente de estas técnicas.

\subsection{Modelado}

El carácter plástico y la capacidad de hidratación constante convierten a la arcilla en un mineral cuasi mágico, que otorga al ser humano la posibilidad de modelar objetos mediante varias líneas de manufactura. La ausencia de marcas superficiales horizontales y paralelas, así como las características granulométricas de las secciones, parecen manifestar que la práctica cometida para el levantado de las cerámicas de Cogotas I no estaba supeditada a elementos de rotación. A mano pues, y empleando hábilmente como gesto técnico la superposición de rollos de columbí, 1@s alfarer@s elaborarían la mayoría del ajuar cerámico que les caracteriza como cultura. La identificación inequívoca de trazas planas de rotura, secciones cóncavas y perfiles con puntos de intersección, descartarían la ejecución de otras técnicas en el modelado, manteniendo únicamente como alternativa el ahuecado simple para la realización de piezas de pequeño tamaño. La sencillez de fabricar recipientes simples a través de un pellizcado discontinuo con los dedos índice y pulgar (Rice 1987), convierten a esta última 
técnica citada en una de las estrategias etnográficas más comunes y extendidas (Gosselain 1995; Livingstone 2007; Roux 2016). Además, la presencia de superficies ligeramente discontinuas y fracturas verticales leves en los bordes de ejemplares de dimensiones reducidas, confirmaría su conocimiento diagnóstico en la Edad del Bronce. En cualquier caso, las operaciones estratégicas (Lemmonier 1992) tomadas para acometer el modelado parecen responder a un grado alto de pericia técnica y formal. Realmente, no es fácil la distinción de fallos técnicos y señas que muestren una escasa destreza en la confección de formas, tales como deformaciones asimétricas y cambios continuos de espesor, bordes irregulares o bases gruesas y agrietadas.

La observación de una orientación preferencialmente paralela de los desgrasantes de la matriz a las paredes del fragmento, nos indica a su vez, el elevado dominio tecnológico y el cúmulo de saberes de1@s artesan@s cogoteñ@s. Esta disposición evidencia la ejecución de toda una serie de presiones laterales sobre los cuerpos en estado fresco, seguramente con el propósito de eliminar burbujas de aire surgidas durante las acciones del modelado, y para ayudar a la defloculación del agua interna presente en la arcilla $(\mathrm{Ca}-$ pel y Delgado 1978; Woods 1985; Gibson y Woods 1990; Velde y Druc 1999; Cau et al. 2004; Berg 2008) o para aumentar la resistencia frente a quebrantamientos o craquelados (Schiffer y Skibo 1997).

Posteriormente, durante el secado, cuando los recipientes adquieren la textura de cuero (Calvo et al. 2004), serían aplicados los correspondientes tratamientos de superficie y configurados los complejos esquemas decorativos (Lám. 2). En primer lugar, se procedería indistintamente a bruñir y alisar las capas exteriores, con la intención de sellar porosidades surgidas a causa de la deshidatación (Echallier 1984) y regularizar con cariz estético el acabado final de los vasos. Las decoraciones se realizarían a continuación, circunstancia que deducimos al no encontrar ninguna evidencia macroscópica que pruebe lo contrario, como la presencia en los márgenes de éstas, o en su interior, de restos de barro originados por la fricción de cantos rodados o paños de cuero. El examen gestual detallado de las decoraciones ha confirmado que en Las Cogotas se aprecian a nivel genérico las mismas que en otros asentamientos coetáneos (Abarquero Moras 2005;
Blanco González 2015b). Nos referimos concretamente al boquique, la incisión, la excisión y múltiples modalidades de impresión, todas ellas ejecutadas con maestría para la creación de motivos diversos, siempre concentrados en zonas visibles, como interiores de labios, bordes o cuellos.

La que designamos con el término de boquique -o punto y raya- es la que más se repite en la panoplia gestual manejada por1@s alfarer@s del sitio de las Cogotas. Con ella se distinguen líneas verticales y horizontales (Lám. 2: 1989-41-3163, 1989-41-3218, CO1989/Viv.9/4, CO-1989/Viv.9/5), que delimitan o forman campos de zigzags (Lám. 2: CO-1989/Viv.9/2, CO-1989/Viv.9/12, CO1989-41-3126), así como motivos vegetales con desarrollo horizontal (Lám. 2: 1989-413127). La técnica impresa en sus variadas vertientes es la segunda en orden de representación. Entre ellas destaca la impresión mediante punzón (Lám. 2: CO-1989/41/2995, CO1989/41/3163, CO-1989/Viv.9/4, CO-1989/ Viv.9/5, CO-1989/41/3126, CO-1989/Viv.9/5, CO-1989/Viv.9/12), constituyéndose como menos frecuentes las impresiones realizadas mediante peine (Lám. 2: CO-1989/41/3570), media caña (Lám. 2: CO-1989/41/3123) o ungulaciones (Lám. 2: CO-1989/41/2382). A la par, la técnica incisa fue usada igualmente para marcar líneas horizontales y verticales, oblicuas o en zigzags (CO-1989/41/3169, CO-1989-412995, CO-1989/41/3163, CO-1989/41/3174, CO-1989-41-2995, CO-1989/Viv.9/2, CO1989/41/3169, CO-1989/41/3174), conjugándola a veces con la impresión para crear patrones inciso-impresos de espiguilla y reticulado (CO-1989/41/3174). Por último, cabe destacar la técnica excisa, a partir de la cual son extraídas porciones de arcilla para formar composiciones decorativas, y que aparece reproducida en tres de los fragmentos seleccionados, adornados éstos con bandas en zigzags (CO-1989/ Viv.9/2, CO-1989/41/3122) y triángulos contiguos (CO-1989/41/3122).

\subsection{Cocción}

Al igual que para cualquier vasija cerámica, el proceso productivo de Cogotas I finalizaría con la cocción, la etapa más importante y determinante de toda la secuencia. El visionado de sus matrices y pastas cerámicas a través de lupa binocular resalta la preponderancia de tonalidades de cochura negras, grises y pardas 
a

b
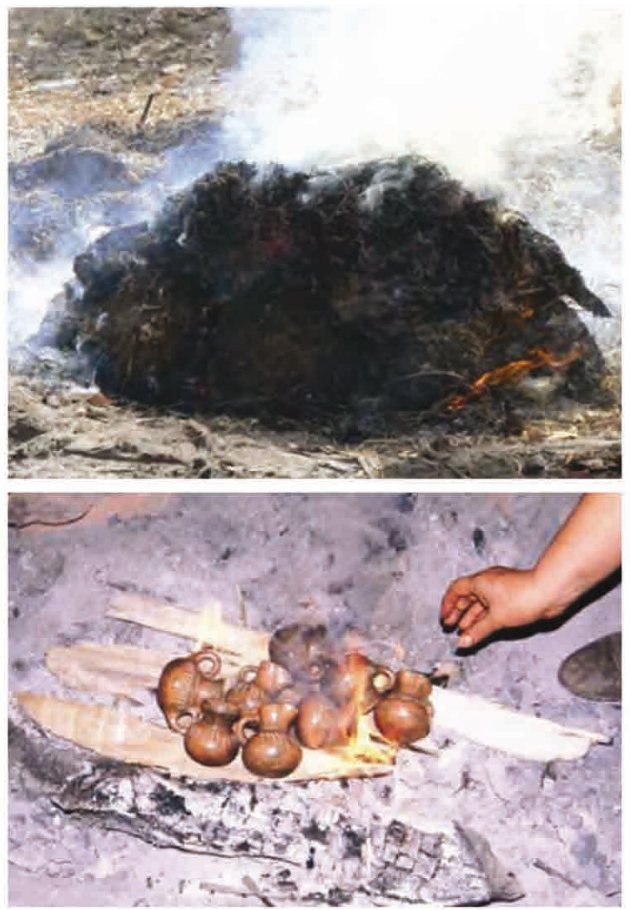
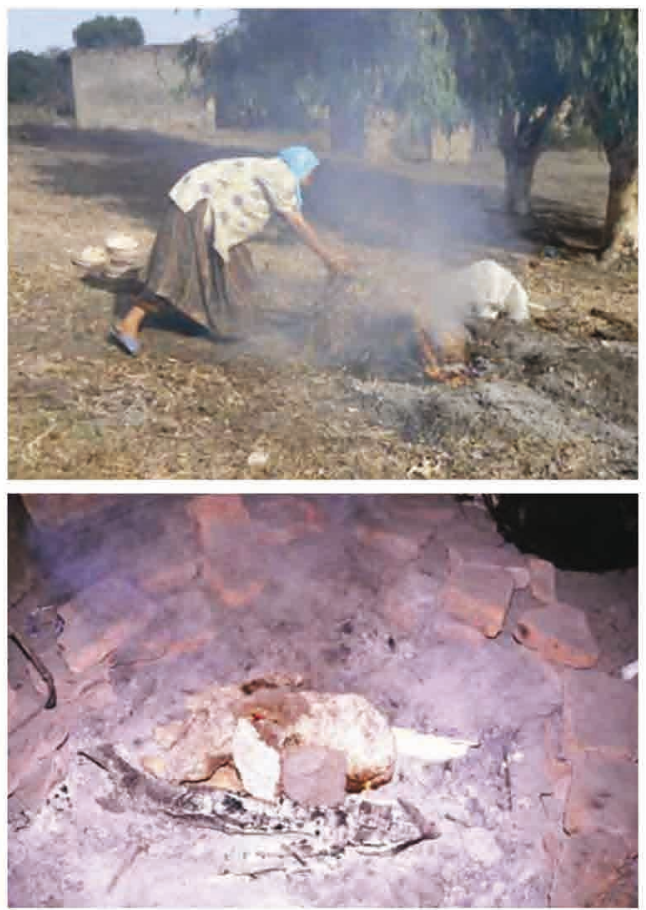

Figura 3. a) Cocción abierta de superficie realizada en Sidi Najam (Túnez). b) Cocción abierta de superficie realizada en Quinchamalí (Chile). (García Roselló y Calvo 2013. Figs. 8 y 9, pp. 130).

oscuras, consecuencia directa de la no entrada de oxígeno en el interior de éstas (Roux 2016). Por contra, la distinción de pequeños matices claros y oxidantes, fundamentalmente en las franjas externas, atestiguaría la absorción del poco oxígeno que conseguiría filtrarse dentro de la atmósfera de cocción (Lám. 1).

La primacía pues de gamas reductoras similares, revelaría la noción única en la Edad del Bronce de cocciones simples y abiertas, cocciones que generan sin problema los cambios físico-químicos que se pretenden, pero que impiden un control satisfactorio de la oxigenación. En esencia, nos encontraríamos ante la realización de hoyos en el suelo a modo de hornos o en superficie, con o sin estructuras arquitectónicas efímeras a su alrededor, y que desafortunadamente dejan escasas o nulas huellas de tipo arqueológico. No obstante, muchas son las referencias etnoarqueológicas (Rye y Evans 1976; May y Tukson 1982; Gosselain 1995; Livingstone 2007; Calvo et al. 2011) y experimentales (Calvo Gálvez 1992) que inciden en sus particularidades, prestando un interés especial en la temperatura que estos consienten alcanzar, no más de $700^{\circ} \mathrm{C}$ (Fig. 3). La constatación de un número considerable de poros vasculares y estriados en las par- tes centrales de las matrices, como producto de la formación de gases y la concentración de partículas arcillosas en el transcurso de la cocción, acreditaría también desde una óptica tecnológica la no superación en este periodo cronológico de curvas de temperatura superiores (Berducou 1990; Freestone 2001; Goffer 2007; Oakley y Jain 2002).

Sea como fuere, y a pesar de llevar a cabo prácticas de cocción consideradas elementales, el conocimiento de la técnica si puede ser calificado como ejemplar. La inexistencia de defectos de cocción en las piezas seleccionadas para este artículo, así como en la mayoría de las encontradas en el yacimiento de Las Cogotas, permite imaginar a personas de experiencia consolidada, garantes de la aplicación precisa de un agregado de gestos técnicos heredados y aprendidos con anterioridad.

\section{4. ¿Tipología o tecnología? La cerámica de Cogotas II}

¿A qué nos referimos exactamente con el concepto de cerámica de Cogotas II? De forma genérica describimos recipientes que suelen lucir decoraciones incisas, elaboradas en es- 
tado fresco por medio de la presión de uno o varios punzones, y que son llamadas comúnmente "a peine" (Álvarez-Sanchís 2010). Fueron descubiertas a principios de 1920 por Juan Cabré en el transcurso de las excavaciones del recinto arqueológico de las Cogotas y desde entonces, las cerámicas peinadas han sido esenciales para teorizar acerca de la idiosincrasia intrínseca de la Edad del Hierro en la Meseta Norte peninsular (Martín Valls 1971 y 1985; González-Tablas 1990; Álvarez-Sanchís 1999 y 2003; González-Tablas y Domínguez Calvo 2002; Sanz Mínguez 1997). Sin embargo, su vinculación primigenia con los vettones, la configuración de la emblemática Cultura de Las Cogotas (Ruiz Zapatero 2004; Álvarez-Sanchís 2008) y la preeminencia de registros materiales mejor definidos, ha generado la proliferación sistemática de estudios enmarcados esencialmente en la Segunda Edad del Hierro y centrados en la consolidación de la cerámica de Cogotas II como un marcador de índole cultural y étnica (Ruiz Zapatero y Álvarez-Sanchís 2002). Efectivamente, son muy pocos los estudios que inciden en su origen y las dimensiones sociales que la propiciaron, un hecho tal vez motivado por la parquedad de datos arqueológicos precisos o bien, por la asunción de parámetros comunes con otros tipos cerámicos como el de Soto de Medinilla, considerado tradicionalmente como su antecedente natural (Martín Valls 1986-1987; Delibes y Romero 1992 y 2011; Seco y Treceño 1993; Esparza 1995).

¿Cuándo, cómo y por qué surge la cerámica de Cogotas II? ¿Qué motivos determinaron el inicio de su manufactura? La no existencia de aproximaciones tecnológicas fuerza a acometer investigaciones en esta dirección, tomando como premisa la búsqueda de nuevas pistas que ayuden a dilucidar tales cuestiones. Ante la imposibilidad lógica de realizar un examen integral del registro cerámico presente en la suma de asentamientos bisagra de finales la Edad del Bronce e inicios de la Edad del Hierro, el yacimiento de Las Cogotas, se convierte por sus condicionantes en el más apropiado para iniciar la senda. Salvando la problemática de su contextualización, el análisis global de la Cadena Técnica Operativa de los recipientes vinculados a dicho periodo de tránsito facilitará la comprensión del mantenimiento o alteración ontológica de múltiples dinámicas sociales, económicas o simbólicas.

\subsection{Selección, extracción y preparación de las materias primas}

Respecto a la selección, extracción y preparación de materias primas relacionadas con el proceso de manufactura de cerámicas de Cogotas II advierte semejanzas con las ya apuntadas para la fabricación de recipientes adscritos al tipo de Cogotas I. La aplicación del concepto de área de captación de recursos (Arnold 2006) deja entrever un acopio local y vinculado a ecosistemas cercanos. El río Adaja y el Arroyo Rominillas se constituirían como las principales fuentes de aprovisionamiento de sedimentos arcillosos neógenos, mientras que bosques y cauces fluviales circundantes, serían explotados con la misión de conseguir combustible para la cocción de las piezas, agua para la preparación de la arcilla y recursos de naturaleza lítica u ósea para la fabricación de útiles (Fig. 2).

La cuantificación de los desgrasantes existentes en las matrices cerámicas evidencia también una elaboración concienzuda de las arcillas seleccionadas. La identificación en las matrices de clastos con distinta densidad, unida a no tener que manejar grandes cantidades de mineral para la posterior manufactura, apuntan a la utilización de tamices con mallas de rejilla fina para eliminar impurezas. Asimismo, el estudio pormenorizado de las pastas cerámicas, consiente la definición de grupos distintos en función de la cuantía de desgrasantes en su interior:

Grupo A: Conformado por recipientes con proporciones que fluctúan entre el $2 \mathrm{y}$ el $15 \%$. Un intervalo que está compuesto por la suma de muestras tomadas en vasos a peine, decorados o no, pero con signos evidentes de tratamientos de bruñido y alisado (n ${ }^{\circ}$ CO-1989-41-3621; CO-1989-41-3103; CO-1989-41-3131; CO-1989-41-3480A; CO-1989-41-3480B; CO-1989-24-263; CO-1989-41-3008; CO-1989-41-3015; CO-1989-41-3016; 33410; 3481A MAN).

Grupo B: Integrado por contenedores cuyo rango oscila entre el 30 y el $50 \%$. Todos ellos vinculados a formas relacionadas con el almacenaje o la preparación de alimentos, tales como orzas, ollas o Jarras $\left(\mathrm{n}^{\mathrm{o}}\right.$ CO-1989-24-697; 35533；35531；3481C MAN). 


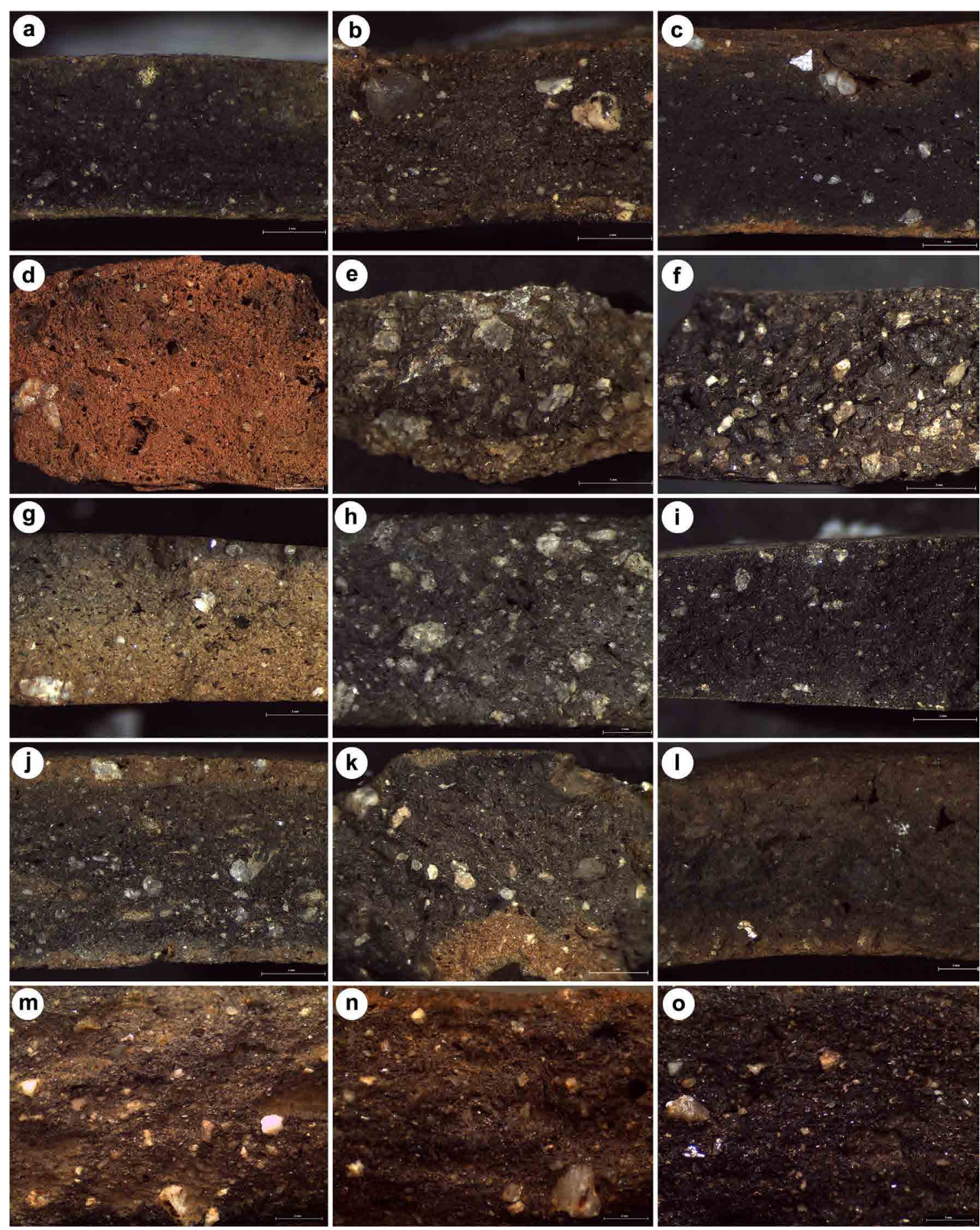

Lámina 3. Microfotografías obtenidas mediante lupa estereoscópica del conjunto de vasijas de Cogotas II procedentes del sitio de las Cogotas (Cardeñosa, Ávila), siendo: a) 1989-41-3621; b) 1989-41-3103; c) 1989-41-3131; d) 33410; e) 35533; f) 35531; g) 3481 (A); h) 3481 (C); i) 1989-41-3480 (A); j) 1989-413480 (B); k) 1989-24-263; l) 1989-24-697; m) 1989-41-3008; n) 1989-41-3015; o) 1989-41-3016 MAN. (Autores). 


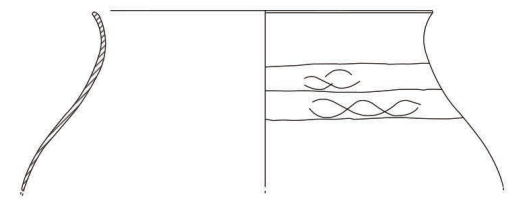

a

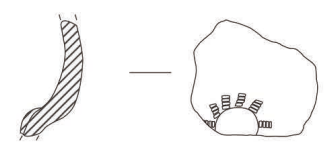

b
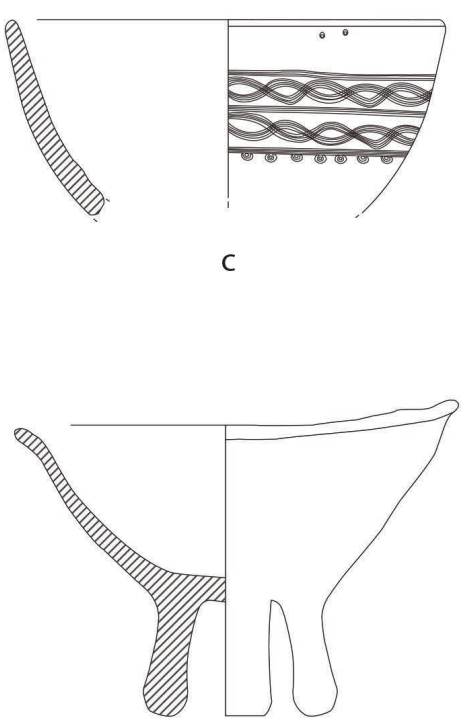

d

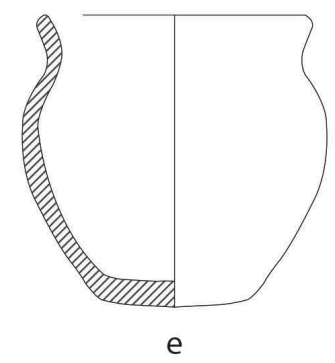

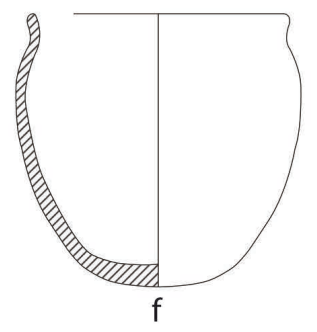

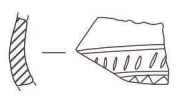

g

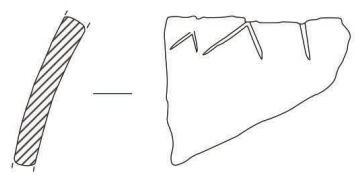

$\mathrm{h}$

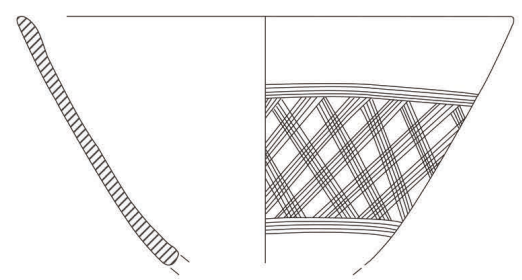

i
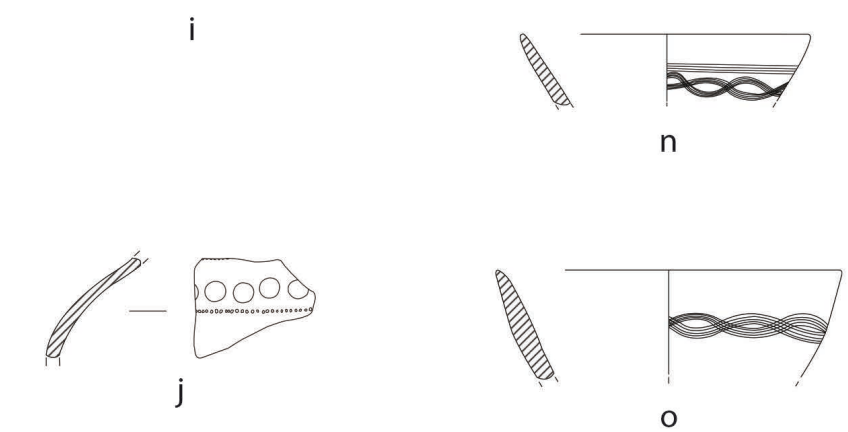

Lámina 4. Conjunto de contenedores adscritos a Cogotas II procedentes del sitio de las Cogotas (Cardeñosa, Ávila), siendo: a) 1989-41-3621; b) 1989-41-3103; c) 1989-41-3131; d) 33410; e) 35533; f) 35531; g) 3481 (A); h) 3481 (C); i) 1989-41-3480 (A); j) 1989-41-3480 (B); k) 1989-24-263; 1) 1989-24697; m) 1989-41-3008; n) 1989-41-3015; o) 1989-41-3016 MAN. (Autores). 

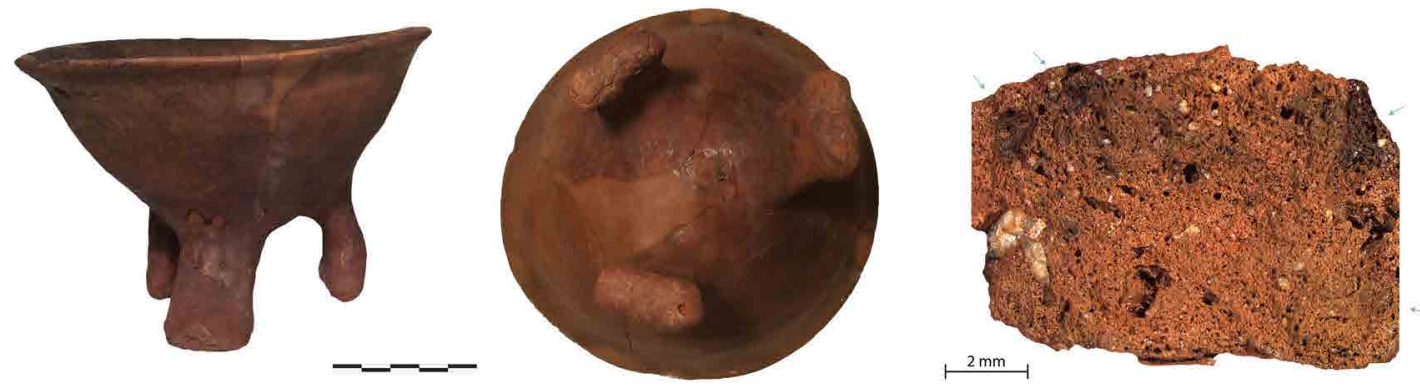

Figura 4. n 33410 MAN. Detalle de signos evidentes de exposición reiterada al fuego en su parte basal, ligeramente vitrificada. (Autores).

A diferencia de lo probado para Cogotas I, la lectura de los datos esta vez sí corroboraría un vínculo fuerte de correspondencia entre número de desgrasantes y signos formales, dando pie a la interpretación de decantaciones concretas a partir de usos específicos (Láms. 3 y 4). Además, el reconocimiento visual en las matrices de clastos con ángulos y aristas verticales y sin señas de rodamiento, confirmaría la más que probable añadidura de cuarzos y micas machacadas. La constatación etnoarqueológica de esta práctica en comunidades preindustriales (Livingstone 2007; Djorjevic 2013) reforzaría esta presunción, que cobraría aún más sentido si cabe, si la ligamos a la somatización de marcas de fuego en bases y cuerpos, fruto del acercamiento directo a fuentes de calor. Por el contrario, resulta extremadamente raro observar indicios de exposición en recipientes ornamentados y con superficies tratadas, concentrándose la inmensa mayoría de éstos en un conjunto amalgamado que por su morfología ha sido asociado a las facies más tardías del Bronce y más recientes del Hierro. Merece la pena destacar a modo de ejemplo un cuenco trípode de tres pies ( $n^{\circ} 33410$ MAN) (Fig. 4), presumiblemente hallado en la vivienda 3 del poblado de Las Cogotas (Cabré 1930: 48; Barril Vicente 2007: 61). Vinculado cronológicamente y en primera instancia con la influencia tardía de la cultura de Campos de Urnas en la Meseta (Almagro Gorbea 1977; Ruiz Zapatero 1979) o el fenómeno orientalizante (Barrio Martín 1987), este vaso concentra -sobre todo en los soportes que lo sustentan- zonas abizcochadas, vacuolas y señales continuadas de vitrificación, defectos poco comunes en otros que han sido considerados del mismo tipo pero que se encuadran en momentos posteriores de la primera y la segunda Edad del Hierro (Álvarez Sanchís 1999: 79; Sanz Mínguez 1997: 230). El criterio de multifuncionalidad se difuminaría progresivamente, dando paso a procesos de preparación individualizados, que aparte de tener en cuenta el gusto por una estética formal determinada, valorarían la tarea primaria a desempeñar. La presencia en Cuéllar de cuencos trípode de "calidades de
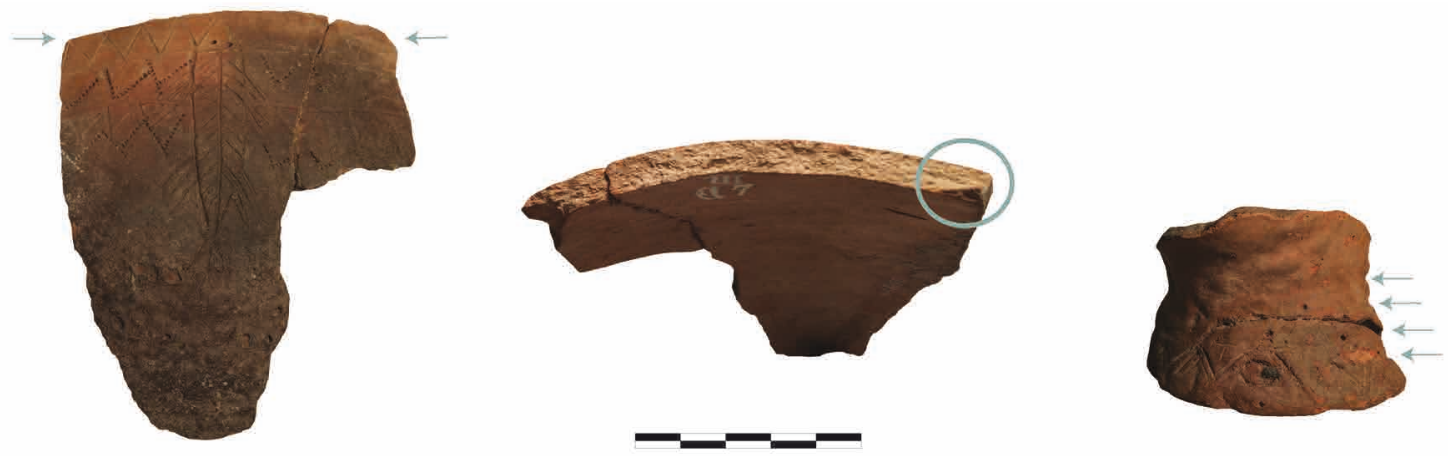

Figura 5. no 35490 MAN. Trazas que evidencian el empleo de rollos de columbí como técnica de modelado. Fracturas horizontales que dejan al descubierto puntos de unión, haciendo factible la determinación del grosor de los cilindros de barro manufacturados para tal fin. (Autores). 
acabado diversas, siendo mayoritarias las de factura tosca o grosera" (Barrio Martín 1987: 105), argumentaría igualmente la implantación paulatina de este cambio tecnológico.

El pisado y amasado, como paso previo al levantado de los modelos ligados al concepto de Cogotas II, sería una constante ejercida a conciencia. Así lo indicaría la compactación de las partículas de arcilla que articulan la matriz y la distribución regular de los desgrasantes naturales o añadidos. La no identificación de huecos por burbujas de aire y nudos a causa de durezas dispares, da cuenta de su calidad y resistencia considerables.

\subsection{Modelado}

El levantado de las piezas cerámicas de Cogotas II, no requeriría de la necesidad de generar energía cinética. Imitando gestos adquiridos y a través de la superposición de rollos de columbí (Fig. 5), confeccionarían el grueso de su panoplia cerámica. Una práctica generalizada a tenor de la identificación de un buen número de elementos diagnósticos, que del mismo modo revalidan el conocimiento del ahuecado simple para la obtención de recipientes minúsculos. L@s alfarer@s productores de Cogotas II manejarían en esencia dominios técnicos idénticos a los originarios de etapas anteriores, innovando sólo y con carácter exclusivo en los perfiles y volúmenes de las formas creadas. Es indiscutible que en el transcurso del Bronce Final y los primeros decenios de la Edad del Hierro, se advierten cambios sustanciales a nivel convencional que dejaron huella, permitiendo apreciar desde una óptica técnica múltiples grados de destreza o habilidad:

Grado deficiente: Visualizado en vasijas con cuerpos irregulares y de grosor considerables, muy pesadas, bordes mal terminados, fuertes asimetrías y signos constantes de reparaciones continuadas en carenas o cambios de dirección ( $\mathrm{n}^{\circ}$ CO-1989-41-447; CO-1989-41-2083; CO-1989-41-2084; CO-1989-41-2227; 33423; 35490; 35491; $35500 ; 35502 ; 35505 ; 35506 ; 35535$; MAN) (Lám. 5).

Grado aceptable: Presente en piezas que guardan un mejor acabado, aunque en ellas todavía sea frecuente encontrar patrones ligeramente asimétricos y trazas inequívocas de retoque secundario $\left(\mathrm{n}^{\circ} 3534 ; 33424\right.$; 35478; 35488; 35492 MAN) (Lám. 6).
Grado óptimo: Vigente en ajuares cerámicos bien definidos, siendo imposible percibir rastro alguno de imperfecciones o arreglos posteriores ( $\mathrm{n}^{\mathrm{o}} 33433 ; 35580$; 1989-24-693 MAN) (Lám. 7).

En Las Cogotas, por tanto, distinguiríamos tres grupos distintos de cerámica de Cogotas II, que pese a no mantener estructuras comunes en el savoir faire formal, sí compartirían rutinas tecnológicas de tradiciones anteriores. Aparte de las plenamente circunscritas en torno a las estrategias de modelado, la observación en las matrices de una disposición alineada de los desgrasantes, la ausencia también en éstas de pequeñas cámaras de aire y la poca frecuencia de grietas y cuarteados superficiales en paredes y bordes, nos situarían ante maestr@s en toda regla, que a ciencia cierta perpetuarían determinadas herencias técnicas para experimentar y adquirir nuevos hábitos formales. Estudios etnoarqueológicos recientes en comunidades indias (Gandon et al. 2014) han incidido precisamente en los problemas y dificultades que tienen los especialistas artesanos para reproducir de manera fiel tipos cerámicos no relacionados con sus procesos de aprendizaje. El entramado de categorías de pericia diferenciadas en Las Cogotas bien podría enlazarse con esta realidad, confirmando a su vez que la experiencia no sería una habilidad general sino un dominio específico (Ericsson y Lehmann 1996).

Los trabajos concernientes al tratamiento y decoración de los vasos modelados tendrían lugar justo después, aprovechando la pérdida de plasticidad en el transcurso del secado. En primera instancia serían realizadas las labores de alisado y bruñido, estableciendo con ellas separaciones de funcionalidad claras entre recipientes. De forma análoga al proceso de decantación, habría una concordancia entre funcionalidad y gesto técnico, siendo ésta cada vez más recurrente con el paso del tiempo. La intensidad y el recibimiento de fricciones constantes en estado de cuero parecen estar reservados a las piezas consignadas preferentemente para el consumo, mientras que la ejecución de un alisado leve en instantes inmediatos a la manufactura, serviría sólo para impermeabilizar las que fueron diseñadas para cocinar o almacenar (Fig. 6).

Los esquemas decorativos documentados para la cerámica de Cogotas II destacan por su complejidad, así como por la alternancia 

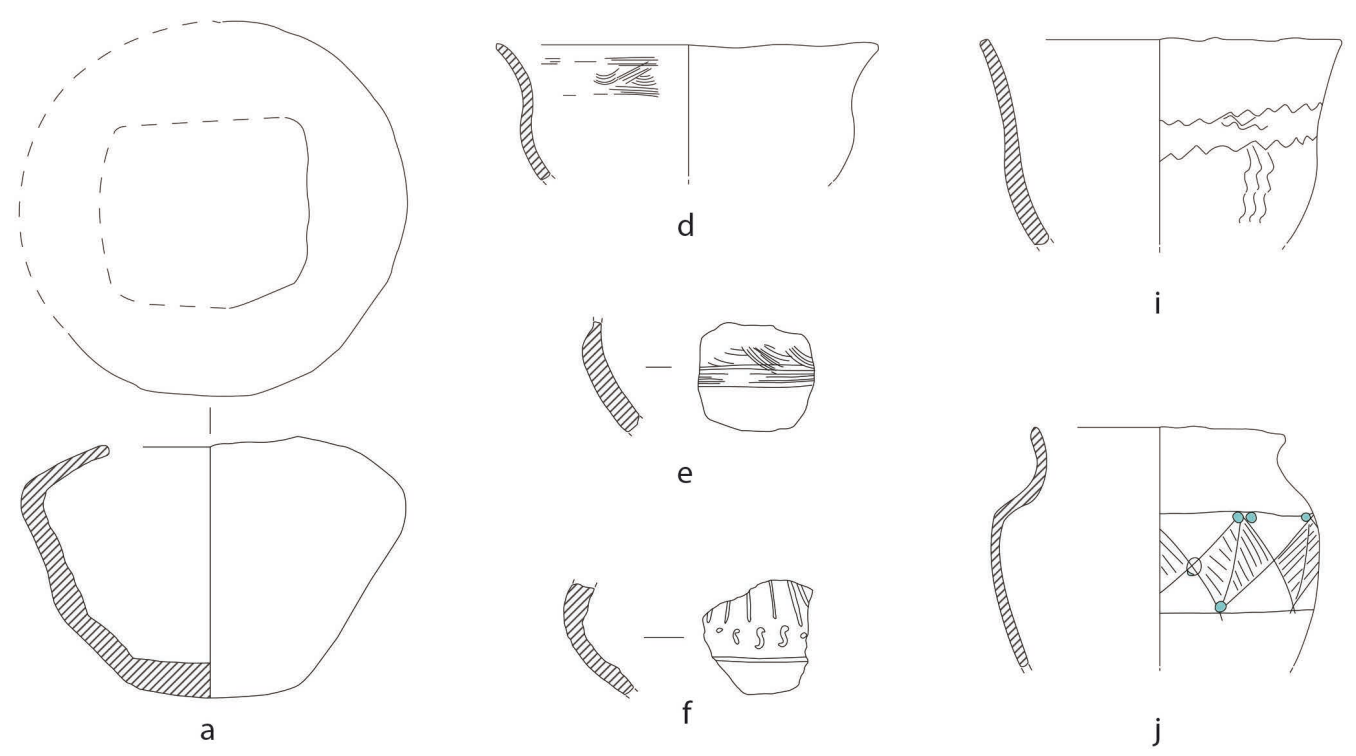

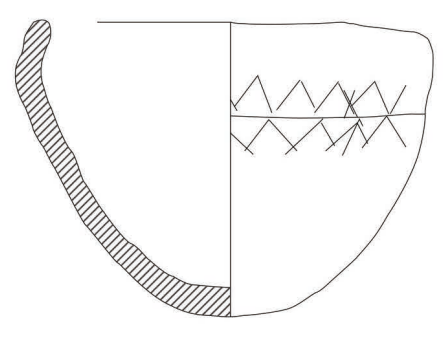

b

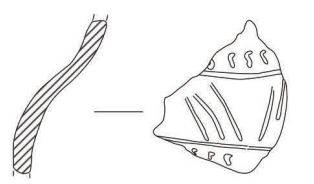

g

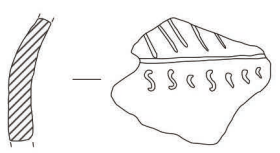

$\mathrm{h}$
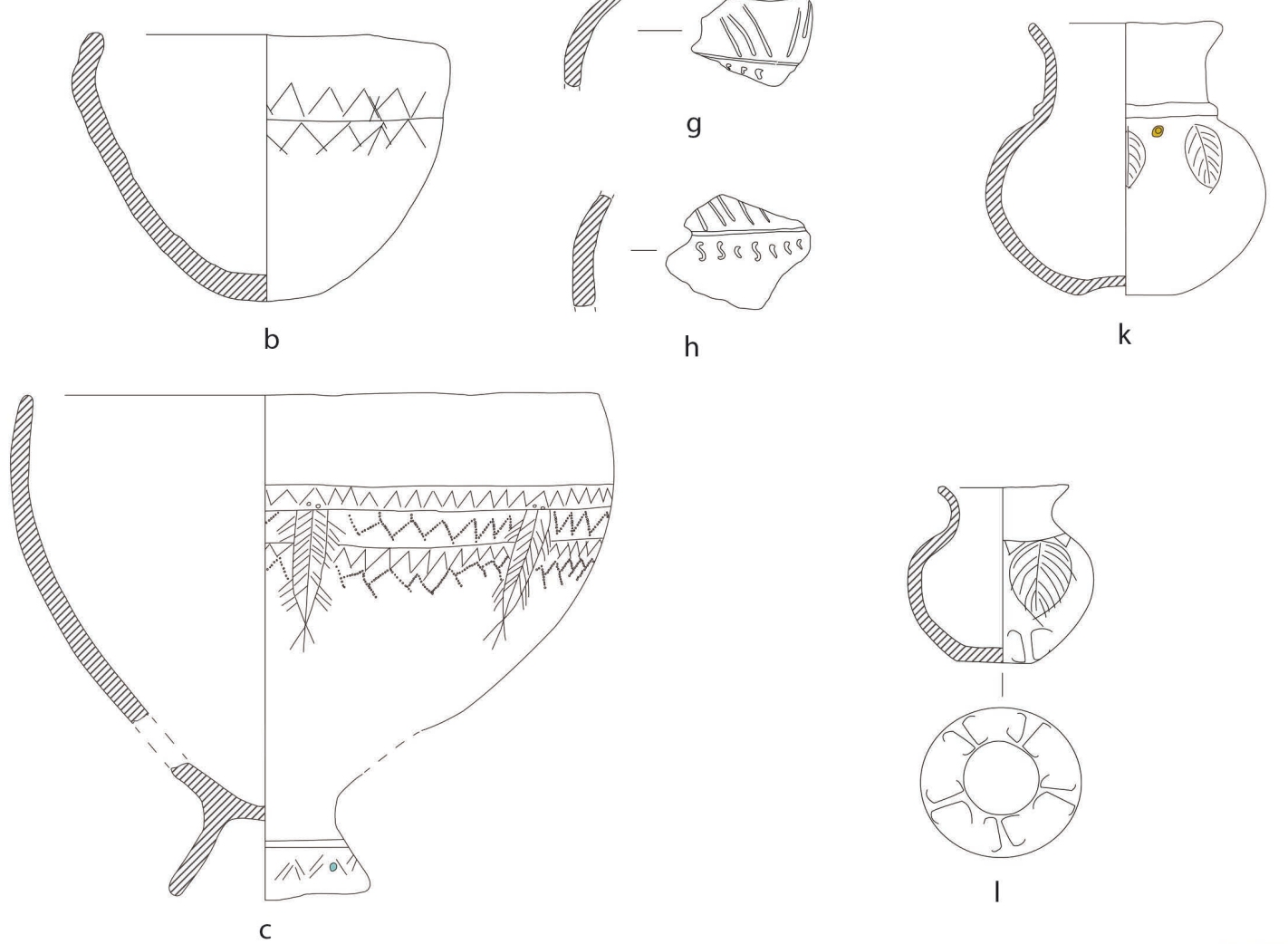

Lámina 5. Grado deficiente de modelado en contenedores de Cogotas II procedentes del sitio de las Cogotas (Cardeñosa, Ávila), siendo: a) 35535; b) 33423; c) 35490; d)1989-41-2083; e) 1989-41-2227; f) 35506; g) 1989-41-447; h) 35505; i) 1989-41-2084; j) 35491; k) 35500; 1) 35502 MAN. (Autores). 


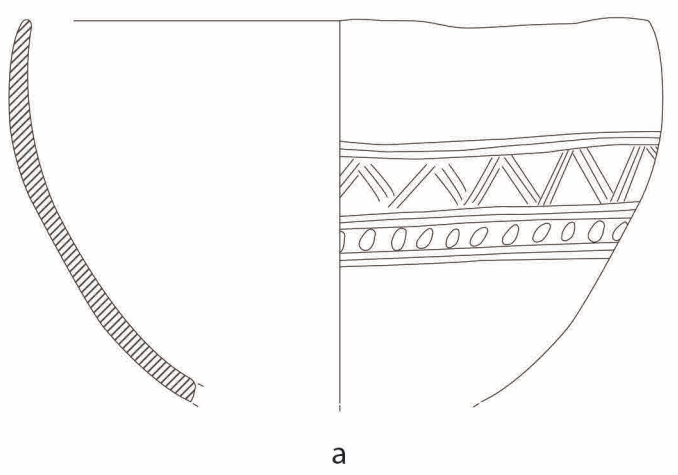

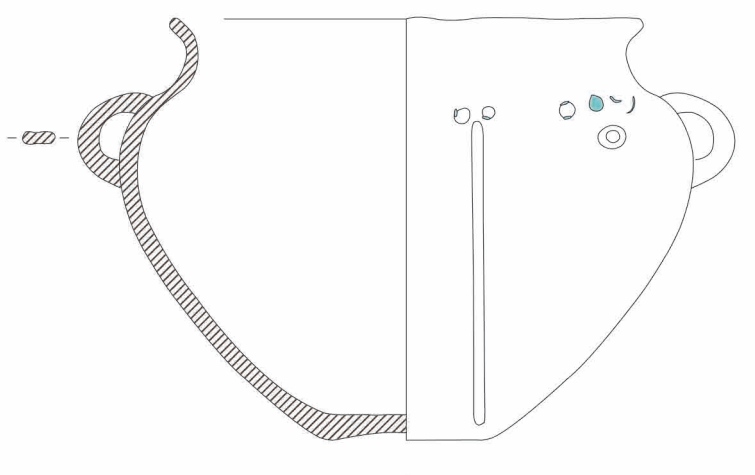

b
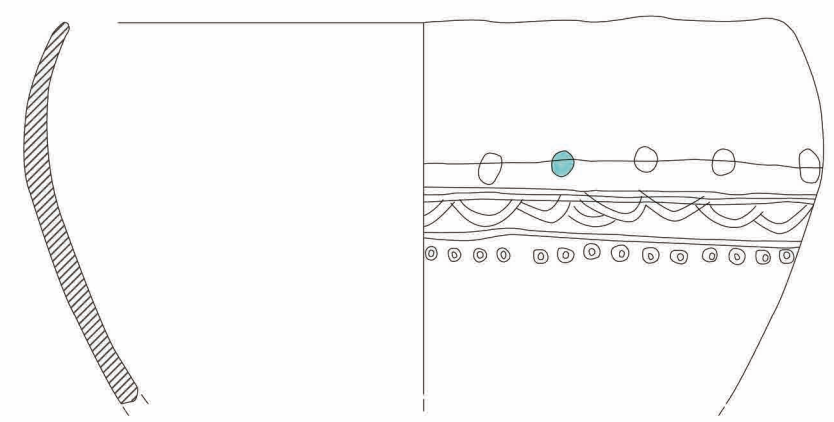

C

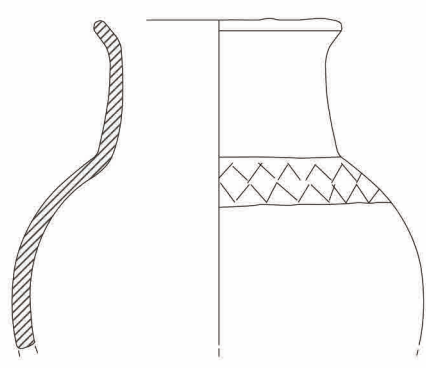

d

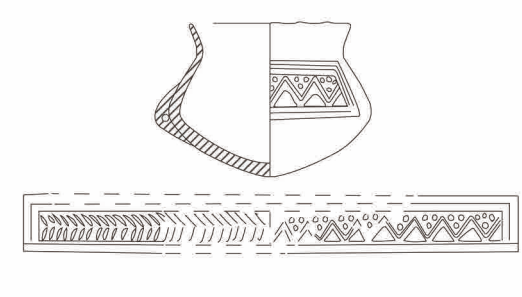

e

Lámina 6. Grado aceptable de modelado en contenedores de Cogotas II procedentes del sitio de las Cogotas (Cardeñosa, Ávila), siendo: a)33424; b) 35488 c)35492; d) 35478; e) 3534 MAN. (Autores). 

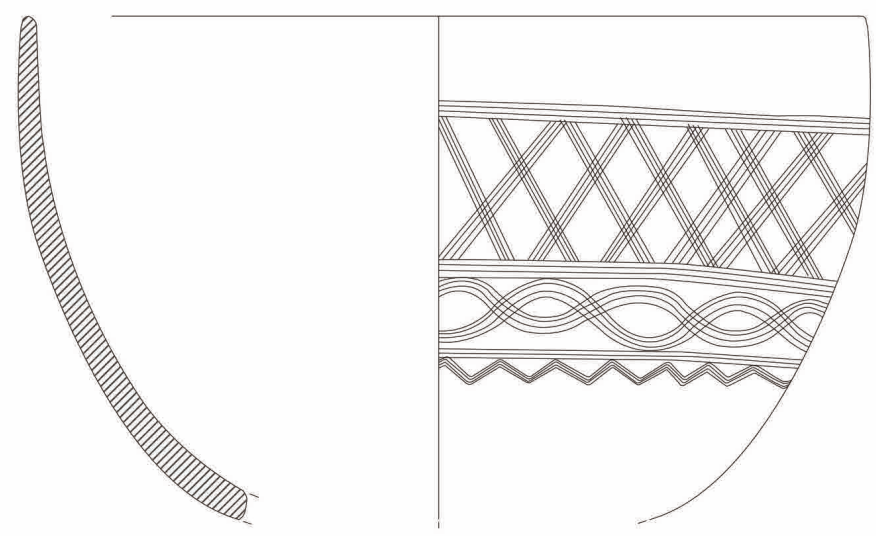

a
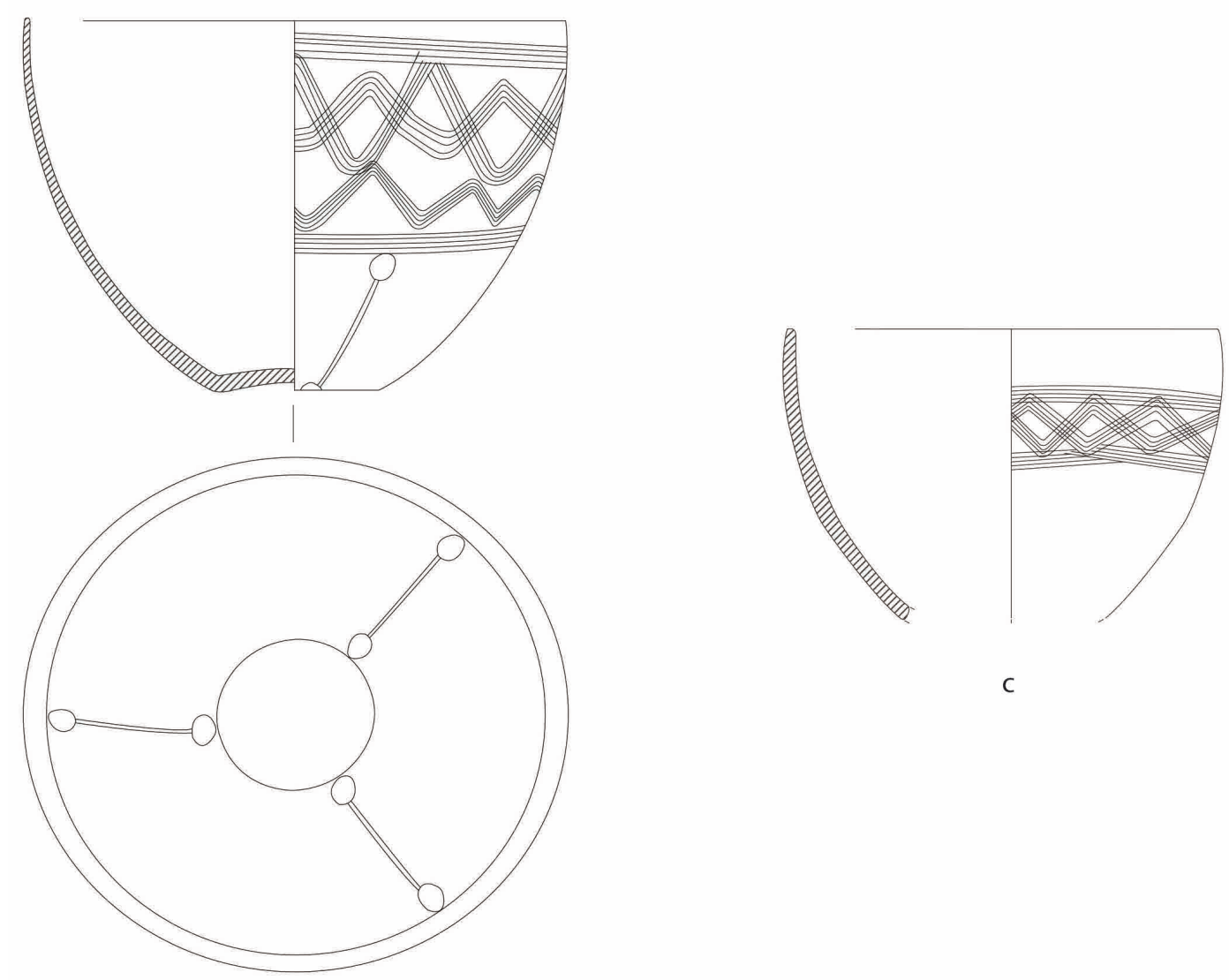

b

Lámina 7. Grado óptimo de modelado en contenedores de Cogotas II procedentes del sitio de las Cogotas (Cardeñosa, Ávila), siendo: a) 33433; b) 1989-24-693; c) 35580 MAN. (Autores). 

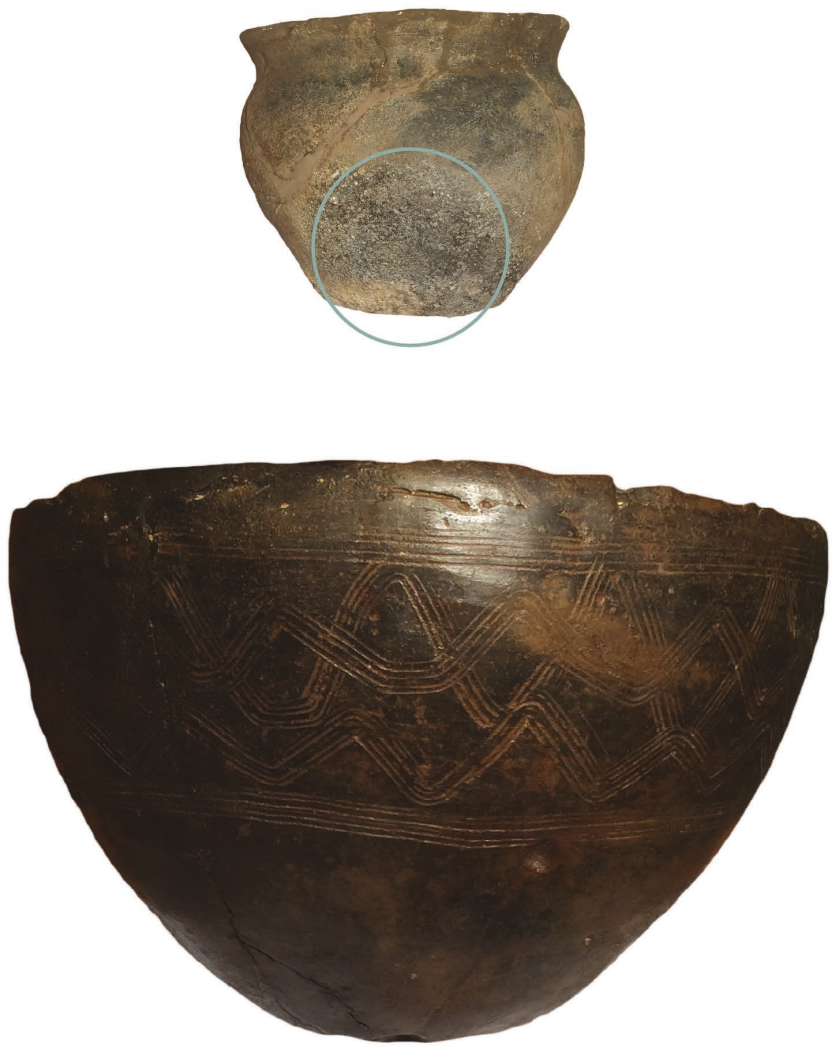

Figura 6. (Parte superior) no 35533 MAN. Forma cerámica con signos elementales de alisado. Además, en ella pode-mos percibir con claridad huellas evidentes de una exposición reiterada al fuego. (Parte inferior) n CO-1989-24-693 MAN. Forma cerámica que permite apreciar perfectamente la práctica de un bruñido concienzudo que le otorga un aspecto cuasi metálico. (Autores).
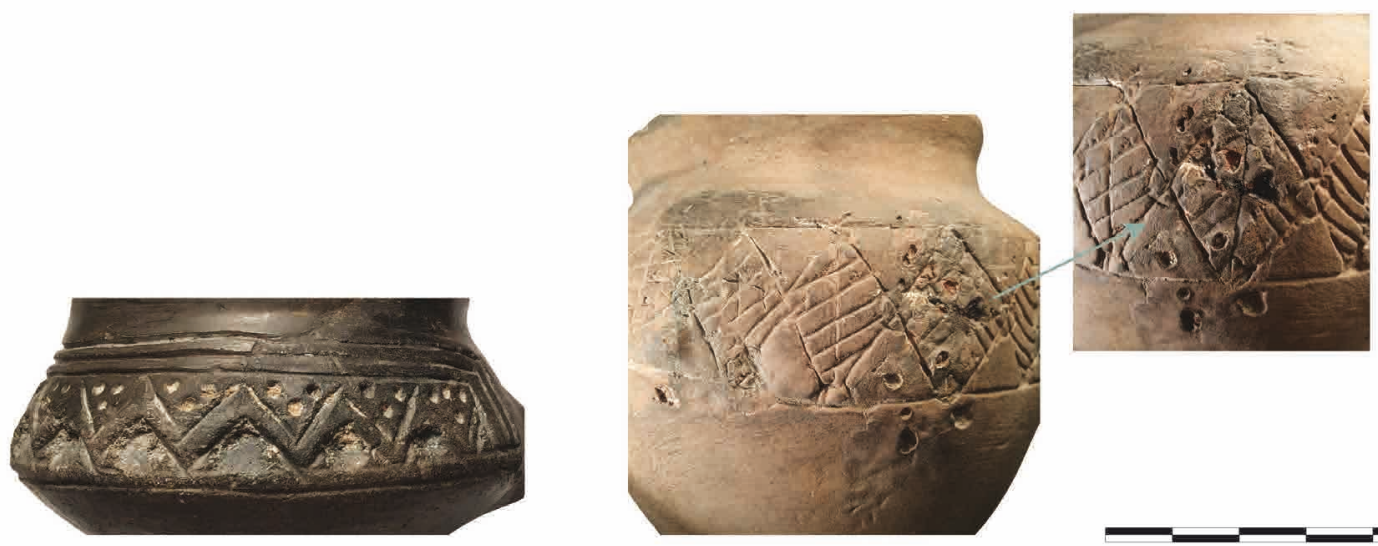

Figura 7. (Izquierda) $n^{\circ} 3534$ MAN. Detalle de técnica decorativa excisa, en la que apreciamos un nivel limitado de pericia técnica. (Derecha) $n^{\circ} 35491$ MAN. Detalle en el que podemos observar vacuolas e incipientes vitrificaciones en la superficie, como consecuencia de pericias técnicas deficientes en lo que se refiere a la aplicación de elementos metálicos. (Autores). 

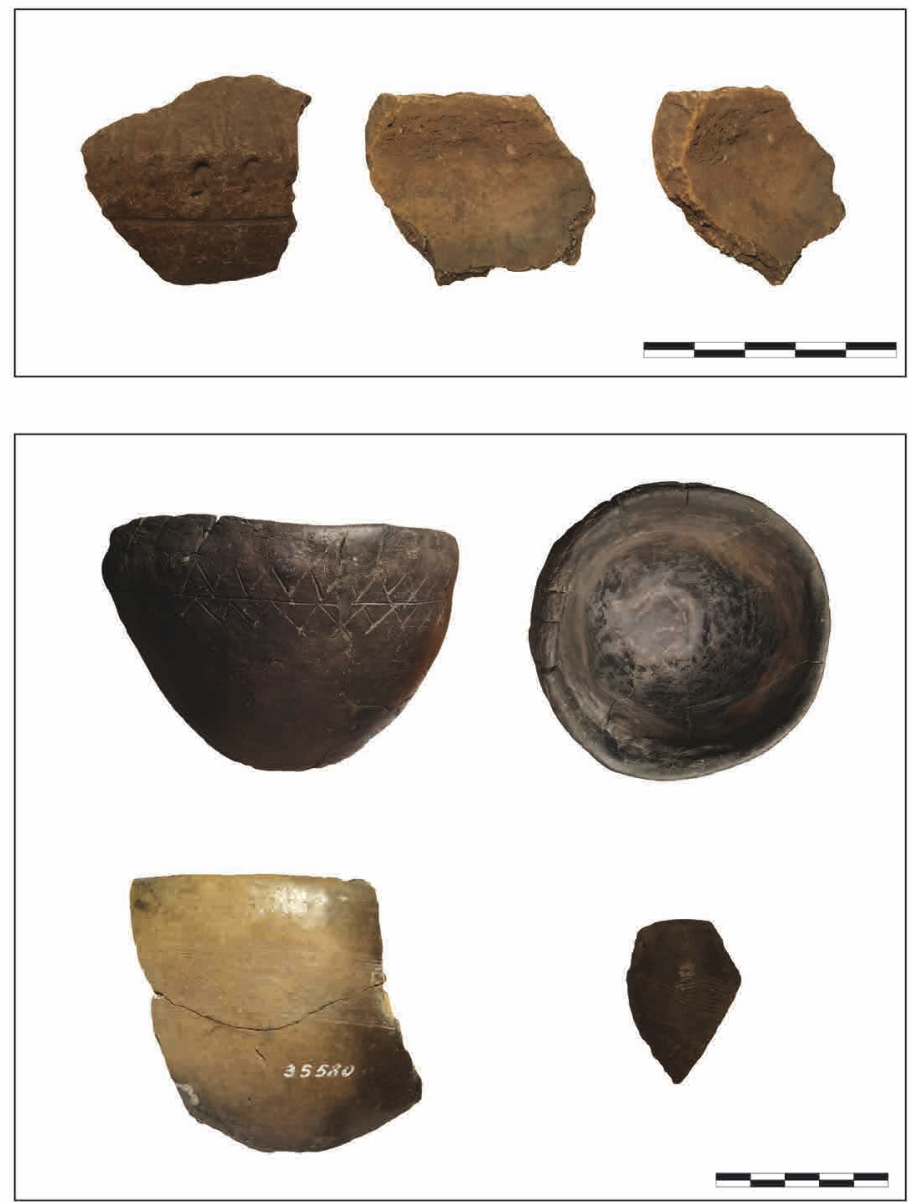

Figura 8. (Parte superior) no 35506 MAN. Fragmento cerámico en el que es posible apreciar signos de continuas reparaciones a posteriori, consecuencia de un deficiente grado de pericia técnica (Parte central) no 33423 MAN. Forma cerámica que presenta marcas evidentes de una pericia técnica limitada. (Parte inferior, izquierda y derecha) no 35580; CO-1989-41-3016 MAN. Piezas cerámicas con un elevado grado de pericia técnica tanto formal como decorativa. (Autores).

para su confección de diversas técnicas. Las incisiones a peine se constituyen como las más comunes y perdurables en el tiempo, pudiendo identificarse igualmente en épocas tempranas y en idéntica proporción, motivos acanalados, incrustaciones de pasta vítrea, inclusiones metálicas e impresiones a modo de estampillas (Láms. 4, 5, 6 y 7). Resulta interesante el avistamiento de pericias técnicas limitadas a la hora de plasmar ornamentaciones acanaladas ( $\mathrm{n}^{\mathrm{o}}$ 3534, 35505, $\left.35506 \mathrm{MAN}\right)$ e insertar apliques vítreos y metálicos $\left(\mathrm{n}^{\circ} 35488,35491\right.$, 35500 MAN), curiosamente en modelos formales que presentan por igual faltas de habilidad (Fig. 7). La adscripción por comparación de éstos a contextos enmarcados en torno al Bronce Final y Hierro antiguo (Cabré 1930; Álvarez-Sanchís 1999; Barril Vicente 2005;
Blanco González 2010a), hace viable la interpretación de sus decoraciones como las primeras expresiones manifiestas de los alfarer@s de Cogotas II. Algo similar sucede con las conocidas como cerámicas inciso-impresas, que en un principio combinan motivos sencillos y mal definidos $\left(\mathrm{n}^{\circ} 33423 ; 35490 ; 35492\right.$; 35502; CO-1989-41-447; CO-1989-41-2084; CO-1989-41-2227; CO-1989-41-3621 MAN), para acabar mostrando con el paso del tiempo secuencias peinadas con un alto grado de destreza (CO-1989-41-3480; CO- 1989-41-3016; 1989-24-693 MAN) (Fig. 8).Además, está atestiguado el empleo de engobes rojizos, obtenidos probablemente del machacado de óxido de hierro y aplicados en conexión directa con el bruñido. Tal vez, la intención de imitar conjuntos cerámicos provenientes de otros territo- 


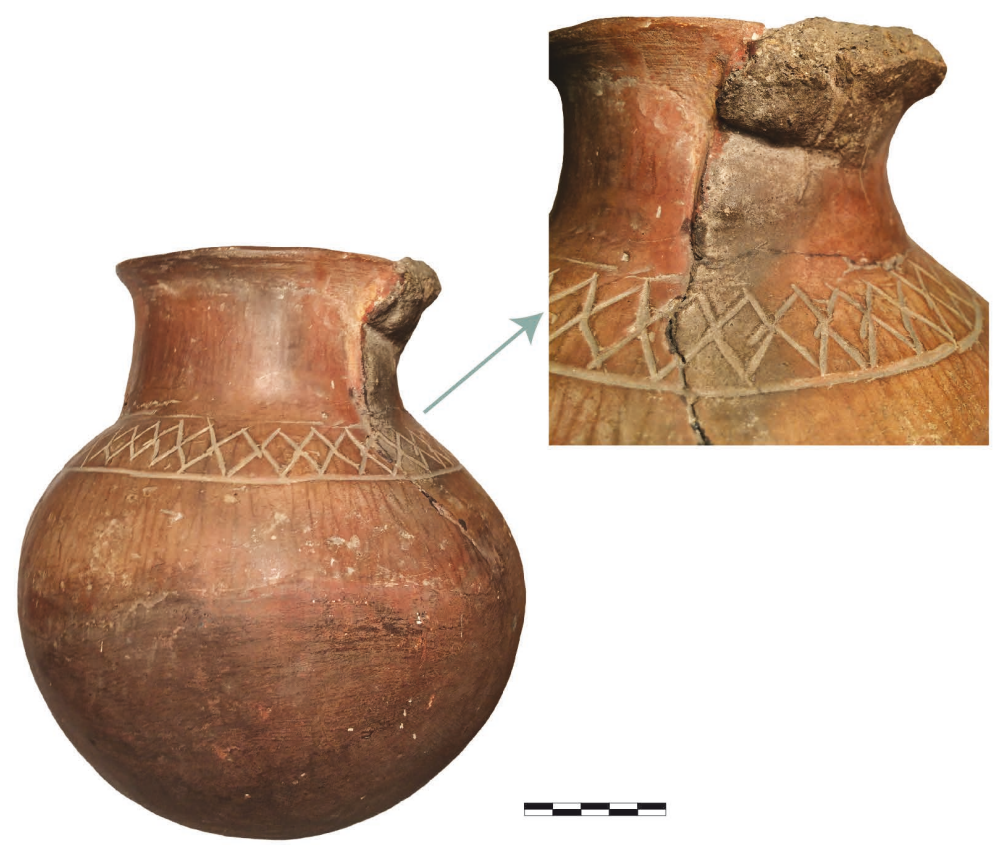

Figura 9. n 35478 MAN. Forma cerámica con huellas claras de engobe oscurecido durante el proceso de cochura y defecto de cocción asociado a éste. (Autores).
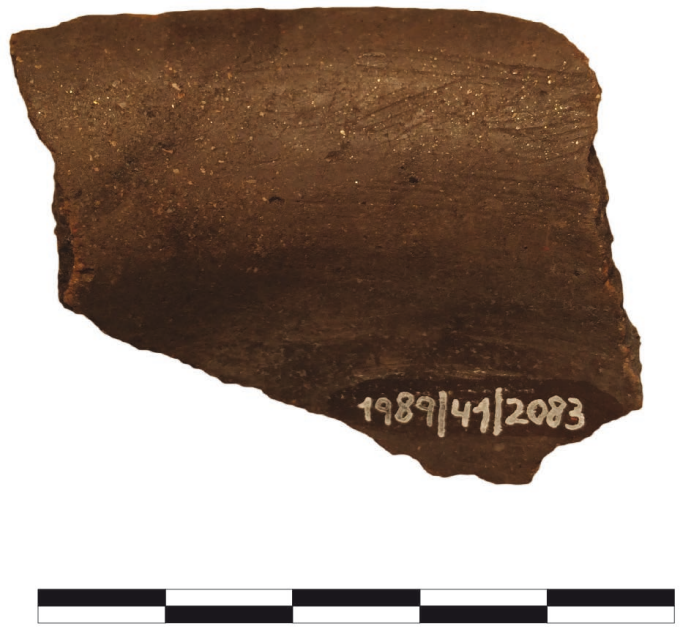

Figura 10. $\mathrm{n}^{\circ} \mathrm{C} 0-1989-41-2083$ MAN. Detalle de decoración peinada en el interior. (Autores).

rios y marcados por un fuerte acento oriental (Celestino et al. 2008; Esparza Arroyo y Blanco González 2008: 86-87) motivaría la realización de estos cromatismos, siempre oscurecidos por el desarrollo de cocciones mixtas $\left(\mathrm{n}^{\mathrm{o}}\right.$ 33410; 35478 MAN) (Fig. 9). Por desgracia y a diferencia de lo acreditado en asentamientos cercanos como el de Los Castillejos de Sanchorreja (González-Tablas y Domínguez Calvo 2002), Las Cogotas no cuenta con el testi- monio directo de piezas con motivos pintados emparentadas con la denominada Cultura del Soto (Palol 1966; Romero Carnicero y Ramírez Ramírez 1996), un indicio quizás debido a la elección por parte de los alfarer@s Cogoteños de representar dichos motivos geométricos mediante figuraciones peinadas. Así lo demostraría técnicamente un fragmento rescatado por A. Blanco (2010a:127, fig. 3a) de los fondos del Museo Arqueológico Nacional $\left(\mathrm{n}^{\mathrm{o}}\right.$ CO-1989-41-2083)33 (Fig. 10). Éste, de notoria fábrica irregular y adornado al interior con dos cordones horizontales que delimitan una franja sogueada e incisa a peine, sería equivalente a otros descubiertos en el Cerro de San Vicente (Martín Valls et al. 1991: 140, fig. 2, 4), Ledesma (Benet et al. 1991:128, fig. 5, 4) o en Los Castillejos (González-Tablas y Domínguez Calvo 2002:91, fig. 56), yacimientos arqueológicos que junto a La Mota y Cuéllar, cuentan incluso con recipientes que combinan en una misma pieza restos de peine y pintura (Álvarez-Sanchís 2010: 307). Entonces, ¿Seguiría teniendo sentido continuar pensando que la cerámica peinada sería la sucesora directa de la de tipo Soto? 


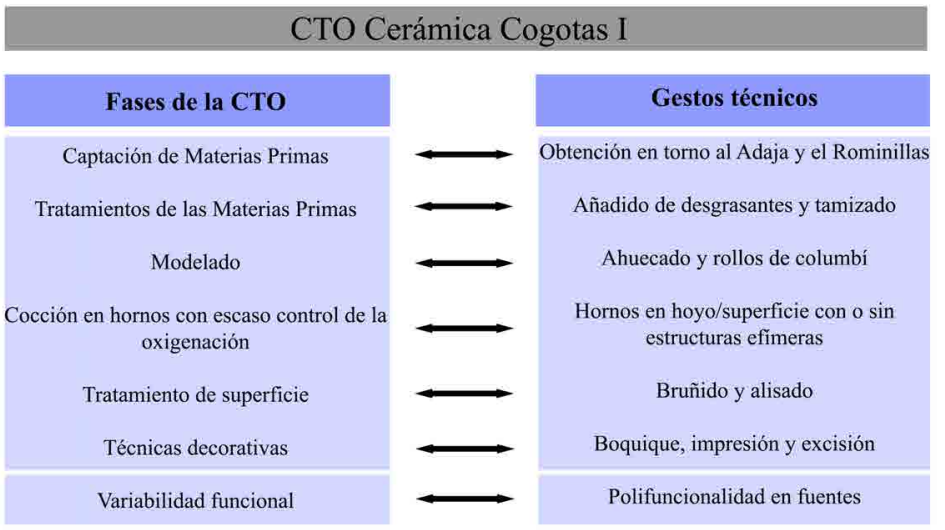

\begin{tabular}{|c|c|c|}
\hline \multicolumn{3}{|c|}{ CTO Cerámica Cogotas II } \\
\hline $\begin{array}{l}\text { Gestos técnicos } \\
\text { Cerámica de Cocina }\end{array}$ & Fases de la CTO & $\begin{array}{l}\text { Gestos técnicos } \\
\text { Cerámica de Mesa }\end{array}$ \\
\hline Obtención en torno al Adaja y el Rominillas & Captación de Materias Primas & Obtención en torno al Adaja y el Rominillas \\
\hline Adición de desgrasantes: cuarzos & Tratamientos de las Materias Primas & Eliminacion de desgrasantes: tamizado \\
\hline Ahuecado y rollos de columbi & Modelado & Ahuecado y rollos de columbi \\
\hline $\begin{array}{l}\text { Hornos en hoyo/superficie con o } \sin \\
\text { estructuras efimeras }\end{array}$ & $\begin{array}{l}\text { Cocción en hornos con escaso } \\
\text { control de la oxigenación }\end{array}$ & $\begin{array}{l}\text { Hornos en hoyo/superficie con o } \sin \\
\text { estructuras efimeras }\end{array}$ \\
\hline Bruñido y alisado & Tratamiento de superficie & Bruñido y alisado \\
\hline $\begin{array}{l}\text { Escasas incisiones a peine, } \\
\text { incisión-impresion }\end{array}$ & Técnicas decorativas & $\begin{array}{l}\text { Incisiones a peine, incisión-impresion, } \\
\text { aplicacion de } \mathrm{Fe}_{2} \mathrm{O}_{3} \text {, apliques metálicos/vítreos }\end{array}$ \\
\hline $\begin{array}{l}\text { Cambios formales respecto a momentos } \\
\text { previos }\end{array}$ & $\begin{array}{l}\text { Cambios/permanencias en aspectos } \\
\text { formales }\end{array}$ & $\begin{array}{l}\text { Cambios formales respecto a momentos } \\
\text { previos }\end{array}$ \\
\hline
\end{tabular}

Tabla 1. Cadenas Técnico-Operativas observadas en la producción cerámica de Cogotas I y Cogotas II.

(Autores).

\subsection{Cocción}

El análisis macroscópico de las pastas cerámicas de Cogotas II respalda la noción de conocimientos técnicos elevados en el proceso de cocción. En las matrices abundan las gamas oscuras, grises y negras, apreciando simplemente en casos expresos coloraciones de naturaleza mixta y oxidante (Lám. 3). No cabe duda, por tanto, que los encargados de ejecutar esta fase decisiva buscarían la fabricación predominante de recipientes reductores, intentando sólo en determinadas ocasiones la consecución específica de tonalidades más anaranjadas. Como ya hemos puntualizado en líneas anteriores, el contacto con otras realidades y el deseo por reproducir rasgos de materialidades foráneas, podría haber incidido en el interés creciente de conseguir gamas de color distintas. No obstante, la persistencia del uso de covachas excavadas en la tierra a modo de hornos, dificultaría con creces el control preciso de la entrada de oxígeno. El registro de un número considerable de ejemplares mixtos y engobes ennegrecidos probaría físicamente esta intencionalidad poco viable. No ocurre lo mismo con aquellas que sí fueron concebidas como reductoras, cocidas éstas a la perfección en atmósferas propicias y carentes de oxigenación. La pericia técnica adquirida y proveniente de generaciones alfareras anteriores dejaría huella, haciendo prácticamente imposible el discernimiento de fallos o defectos de cochura.

Lamentablemente, los trabajos arqueológicos desempeñados en el área de Las Cogotas no han encontrado indicios de estructuras de combustión asociadas a estas cocciones, impidiendo la ratificación de lo expuesto. Aun así, las características particulares de su cultura material nos llevaría a imaginar en el origen de la Edad del Hierro un escenario de trabajo similar al acaecido a finales de la Edad del Bronce. Una perspectiva, que a raíz de la evidencia de una serie de pistas tecnológicas, tardaría re- 


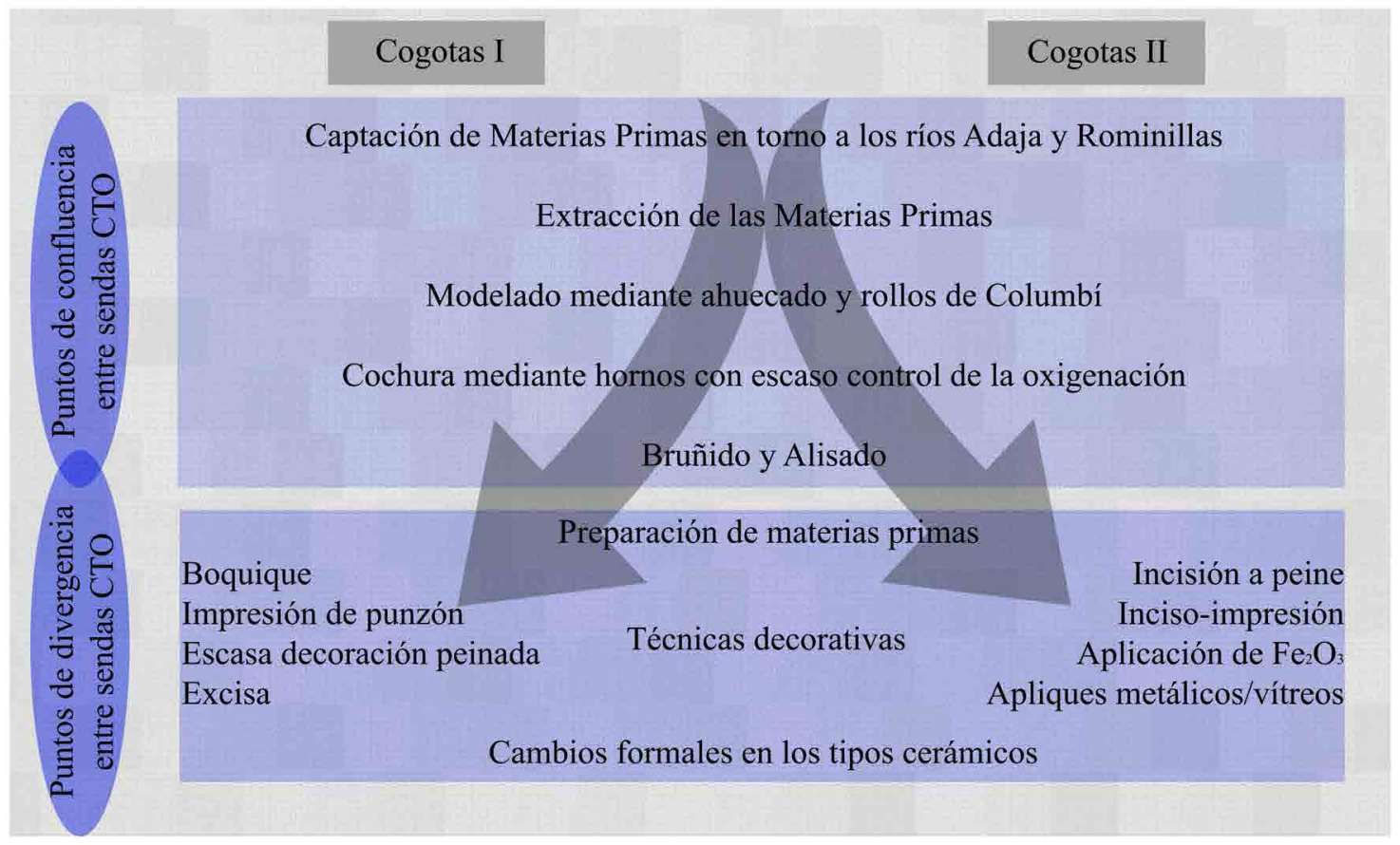

Tabla 2. Puntos de confluencia y divergencia de las Cadenas Técnico-Operativas de Cogotas I y Cogotas II. (Autores).

lativamente poco en cambiar para comenzar a construirse hornos con propiedades diferentes y alcances iguales o superiores a $\operatorname{los} 800^{\circ} \mathrm{C}$. En centurias ulteriores, una serie de transformaciones técnicas proyectarán nuevos métodos de hacer cerámica desconocidos hasta entonces, a través de la edificación de estructuras uni/bicamerales, permanentes o no, capaces de lograr sin problema temperaturas altas y fabricar satisfactoriamente y de forma independiente cochuras individualizadas de cariz oxidante o reductor (Sempere 1992: 191-213).

\section{Cogotas I vs Cogotas II: El valor de la diferencia}

El desglose detallado de cada una de las fases de las cadenas operativas cerámicas de Cogotas I y Cogotas II ofrece la oportunidad de adentrarnos en su "lógica social" (González Ruibal, en prensa). El cómo da pie a investigar parámetros meramente tecnológicos, pero también brinda la posibilidad de secuenciar el vínculo implícito entre el objeto cerámico y las dinámicas sociales que lo configuran como tal. El modo de hacer cerámica, al igual que cualquier acción o conjunto de ellas, está ligado a otras "prácticas o valores sociales" (Gosselain
2011: 223) y, por tanto, inducida por una manera explícita de pensar y concebir la realidad. La comparativa pormenorizada de los procesos productivos de Cogotas I y Cogotas II, da buena cuenta de la existencia de dos tipos de savoir faire bastante bien alineados, aunque estrechamente relacionados entre sí por medio de continuidades y permutas tecnológicas con significado propio. En esencia, la somatización de dos formas distintas de aprender, reproducir o innovar conocimientos alfareros en función de determinadas interacciones y condicionantes sociales (Dobres y Hoffman 1999) (Tab. 1).

¿Qué similitudes podrían ser remarcables? En primera instancia es obligado hacer hincapié en la selección y extracción de las materias primas, donde la coincidencia en ambas producciones es milimétrica. No cabe duda en que para satisfacer sus necesidades de acopio explotarían los mismos ecosistemas locales, dando cuenta a la vez de la relación estrecha de estas gentes con el medio en el que habitaban. Además, la no detección de arcillas u otros elementos de presunción foránea sería una muestra palpable de la ejecución de las tareas productivas cerámicas en sitios cercanos al asentamiento o en su interior. Las comunidades de Cogotas I y Cogotas II, compartirían también la más que presumible no necesidad 
de decantar cantidades abundantes de mineral, optando en consecuencia por la realización de depuraciones con tamizado en pequeñas balsas al uso. La confección de recipientes mediante la técnica del ahuecado y la yuxtaposición de rollos de columbí, igualmente se convierte en una prueba veraz de la vinculación de estas dos tradiciones respecto a un conjunto de patrones técnicos. La documentación de trazas y signos gestuales equivalentes en sendos ajuares, confirmaría su efectivo proceder en marcos temporales distintos. Por último, cabría destacar el empleo en la fase de cocción de nociones y experiencias técnicas análogas, induciendo a la postre la generación de recipientes cerámicos con tonalidades y propiedades de cochura idénticas.

Por contra, el valor de la diferencia incide sobre todo en cuestiones que guardan conexión con un cambio de coyuntura y de entendimiento de la materialidad cerámica. La cadena técnico operativa de Cogotas II concibe nuevos artefactos y diseños decorativos, rompiendo tajantemente con las formas obradas hasta entonces. De ahí, la percepción clara de múltiples grados de habilidad práctica, tanto en representaciones formales como ornamentales, y el intento de conseguir coloraciones rojizas y cocciones oxidantes. Una circunstancia frontalmente opuesta a lo observado en vasos circunscritos a Cogotas I, donde la destreza en cuanto a preconcepciones mentales y modalidades de acción es manifiesta. A su vez, exponencialmente y desde una perspectiva de consolidación conceptual, acabarían siendo añadidas particularidades técnicas según usos y funcionalidades específicas. Ante la premisa de manufacturar piezas supeditadas a esferas concretas de la vida cotidiana, acabarían fijándose dos líneas de producción, cocina y vajilla "fina", mediante el añadido controlado de desgrasantes y la elaboración de tratamientos de superficie diversos.

La aplicación de una lectura transversal, deja entrever la definición de dos comunidades de práctica (Wenger 1998) muy enlazadas por el compartimento de un conjunto de técnicas básicas (Tab. 2). Una realidad propiciada por un régimen de transferencia vertical del conocimiento, que respaldaría el traspaso de conocimientos a la Edad del Hierro de determinados modos de acción por el simple hecho de haber sido siempre así (Gosselain 2011). Por mero conservadurismo cultural, los alfareros de Cogotas II reproducirían un habitus cerámico de disposiciones y reglas operadas desde antiguo (Safa Barraza 2002), modificándolo sólo de manera explícita para adaptarlo a nuevas estructuraciones sociales. El concepto de habitus bourdiano (Bourdieu 1988: 170-1), centrado en las conexiones del individuo y sus agentes (Objetos) con los criterios sociales que lo condicionan, se autodenomina dinámico y favorecedor de cambios técnicos (Bourdieu 1991: 89), para acomodarse a la imposición de otras pautas sociales. En nuestro caso, resulta incuestionable la modificación intencionada de partes del proceso productivo de Cogotas II, para plasmar a nivel material la ruptura social con patrones de tiempos pasados.

El aparente desequilibrio social de las comunidades meseteñas de la Edad del Bronce (Blanco González 2015c: 441), acabaría dando paso en la Edad del Hierro a comunidades plenamente asentadas y homogeneizadas, insertas en procesos de jerarquización reciente (Esparza Arroyo y Blanco González 2008: 89). Inducidamente o no, y por diversos condicionantes, se producirían cambios ontológicos que conllevarían una transformación generalizada de los patrones materiales. Adoptando como hipótesis más plausible la interacción demográfica con regiones ubicadas al sur de Gredos y en los altos del Tajo y Ebro (Blanco González 2010b), las poblaciones del valle del Duero sufrirían un canje identitario que acabaría por sesgar toda relación con creencias y concepciones simbólicas anteriores. La configuración de asentamientos afianzados y estables exigiría paralelamente la creación de toda una cultura asociada, concediendo a la tecnología un papel fundamental dentro del proceso de arraigo y consolidación. El reconocimiento arqueológico en Las Cogotas de recipientes con categorías de destreza diferenciadas, constataría la instauración efectiva de estrategias de conocimiento por transferencia horizontal. El deseo de imitar elementos foráneos conllevaría también una reproducción de sus características formales, motivando la instauración de aprendizajes paralelos nunca antes imaginados. La cerámica de tránsito a la Edad del Hierro está repleta de estadios híbridos y como tal, desde una panorámica tecnológica debería ser considerada como un ensayo. La adquisición definitiva de su preconcepción mental y el automatismo de las operaciones manuales necesarias para su fabricación (Bowser 2000), no llegaría hasta varias generaciones después, cuando la programática de un preciso número 
de actividades técnicas fuera adquirida como una pauta naturalizada (Vidal y García Roselló 2009). Tiene, por tanto, lógica el pensar que los alfarer@s de Cogotas II tantearían diferentes caminos de hacer hasta llegar a precisar el axioma de su cadena gestual. El hallazgo en el castro de cerámicas almagradas, con el objetivo presumible de conseguir coloraciones rojizas u oxidantes, y fragmentos con iconografías novedosas a través de tácticas de acanalado y semi-incisiones, denotaría sin problema el desarrollo de este tipo de actitudes.

El marcado carácter social del savoir faire, al margen de tolerar la elucidación de dos comunidades de práctica como comunidades de identidad (Eckert 2012; Eckert et al. 2015) y resaltar el valor de la cerámica como fuente elemental de códigos visuales (Houbre 2013), consiente disertar acerca del efectivo avance de la individualización. Designado éste como "la suma de decisiones técnicas culturales características de un grupo concreto" (Pelegrin 1985), permite visualizar nuevas estrategias orientadas al apuntalamiento de un mundo supeditado a la jerarquización. La ilustración cíclica del establecimiento de variantes técnicas y profesionalizadas para la ordenación de dos clases cerámicas, así como la reducción metódica de capacidades y tipos de bocas, fortalecería la afirmación de entidades humanas cada vez más dominadas por la imposición de un sistema patriarcal. No obstante, a finales del Bronce y principios del Hierro, todavía contaríamos con una actividad alfarera comprendida en el ámbito de lo doméstico, siendo en tal caso las mujeres las encargadas de transmitir de generación en generación los saberes alfareros. Un supuesto, soportado en gran parte por fuentes de información etnoarqueológica (Livingstone 2007; Calvo et al. 2015), que no cambiaría hasta el tránsito hacia la segunda Edad del Hierro, tiempos en los que el afán por la "fantasía de la individualidad" (Hernando Gonzalo 2012) y la elección de la energía cinética como motor tecnológico, relegarían a la cerámica a mano y su esfera colectiva a un segundo término.

\section{Consideraciones finales}

Parafraseando a Gonzalo Ruiz Zapatero (2007: 39), ¿hubo alguna vez una transición del Bronce al Hierro en el occidente de la Península Ibérica? Al menos, el yacimiento de Las Cogotas ofrece la posibilidad de imaginar un am- biente en transformación continua, en el que muchas cosas cambian y otras permanecen. El contacto y llegada de nuevas gentes a la cuenca del Duero supuso una revolución en todos los sentidos y, a la larga, la imposición de un nuevo orden social. A falta de restos arqueológicos concluyentes y completos, bien por la ausencia de actuaciones o por la pérdida masiva de información en excavaciones decimonónicas, el estudio de la tecnología cerámica de uno de sus asentamientos clave permite entender a grandes rasgos la forma en la que ésta tuvo lugar. $Y$ es que la tecnología, concebida como una herramienta básica donde las haya para el análisis de sociedades pretéritas, demuestra la existencia de una ocupación continuada en Las Cogotas y la metamorfosis identitaria de sus moradores. Abandonando definitivamente discusiones interesadas en la significación de rasgos de estilo, la puesta en práctica de aproximaciones centradas en la relación de los objetos con las personas, recalca la cerámica como un continente repleto de contenido cultural en el que aparte de expresar el sentimiento de pertenencia a un grupo, esconde informaciones relativas al concepto de género o la plasmación de las divisiones sociales y de clase. Probablemente el trabajo alfarero permaneciera en un principio ligado a la esfera de lo doméstico y de lo colectivo, pero es evidente que la consolidación de nuevas creencias y sentimientos de otredad, traen consigo reglas generadoras de individualismo y potenciación de lo masculino frente a lo femenino.

A modo de conclusión, la consecución de un fenómeno potente de hibridación social trajo consigo vidas distintas en los albores de la Edad del Hierro. La comparación con otras dimensiones materiales de yacimientos contemporáneos (Blanco González 2010b; Fabian García y Blanco González 2010; Misiego Tejeda et al. 2005), o atribuidas al propio castro (Barril Vicente 2007; Blanco González 2010a), parecen registrar datos afines con este parecer. No obstante, somos muy conscientes de que aún queda un largo camino por recorrer. La muestra aquí presentada corresponde únicamente a un sitio arqueológico, que si es verdad se considera como un enclave icónico, no representa la totalidad de particularidades que este periodo encierra. Estas páginas tan sólo pretendían ser un punto de partida con el que refutar la sincronía de ocupación del enigmático castro y demostrar la valía de la tecnología para realizar discursos históricos huma- 
nos. Queda abierta pues, una senda repleta de cauces alternativos con los que discutir viejas cuestiones y plantear retos hasta hoy inconcebibles como, por ejemplo, la relación existente entre gestos cerámicos e interacciones demográficas. La búsqueda de más aproximaciones globales debe ser ahora nuestra principal premisa.

\section{Agradecimientos}

La redacción de este artículo no hubiera sido posible sin la ayuda desinteresada del departamento de Protohistoria del Museo Arqueológico Nacional, y en especial a su directora, Alicia Rodero, y su conservadora Esperanza Manso. A su vez, el texto ha sido enriquecido con comentarios aportados por los doctores Gonzalo Ruiz Zapatero, Jesús R. Álvarez Sanchís, Gonzalo Aranda Jiménez y Antonio Blanco González, a quienes desde aquí expresamos nuestra gratitud. De los errores o contrariedades que puedan observarse en el texto, asumimos nuestra entera responsabilidad.

\section{Notas}

3. Antonio Blanco (2010) se refirió a este fragmento de borde con el número de inventario CO-1989-412227. Tras verificar la misma pieza en los fondos del Museo Arqueológico Nacional, hemos comprobado que se trata de un error, siendo por tanto el número de inventario correcto el puntualizado aquí.

\section{Bibliografía}

Abarquero Moras, F. J. (2005): Cogotas I: la difusión de un tipo cerámico durante la Edad del Bronce. Junta de Castilla y León, Salamanca.

Abarquero Moras, F. J. (2012): Cogotas I más allá del territorio nuclear. Viajes, bodas, banquetes y regalos en la Edad del Bronce peninsular. Cogotas I, una cultura de la Edad del Bronce en la Península Ibérica (J.A. Rodríguez Marcos; J. Fernández Manzano, J. eds.), Universidad de Valladolid, Valladolid: 59-110.

Albero Santacreu, D.; Puerta, L. (2011): "Tradición, funcionalidad y materia prima: el núcleo alfarero de Pòrtol (Mallorca)". Actas de las II Jornadas de Jóvenes en Investigación Arqueológica. Libros Pórtico, Universidad Complutense de Madrid, Madrid: 41-47.

Albero Santacreu, D. (2015): Materiality, techniques and society in pottery production. The technological study of archaeological ceramics through paste analysis. De Gruyter Open Ediciones.

Almagro Gorbea, M. (1977): El Pic del Corbs de Sagunto y los Campos de Urnas del NE de la Península Ibérica. Saguntum 12: 89-141.

Almagro Gorbea, M. (1996): L'etá del Bronzo in Iberia: Cronología relativa. Acta Archaeologica 67: 153163.

Álvarez-Sanchís, J. R. (1999): Los Vettones. Bibliotheca Archaeologica Hispana 1. Real Academia de la Historia, Madrid.

Álvarez-Sanchís, J. R. (2003): La Edad del Hierro en la Meseta Occidental. Madrider Mitteilungen 44: 346-386.

Álvarez-Sanchís, J. R. (ed.) (2008): Vettones. Pastores y guerreros en la Edad del Hierro. Museo Arqueológico Regional, Comunidad de Madrid, Madrid.

Álvarez-Sanchís, J. R. (2010): La cerámica con decoración a peine, de 'fósil guía' a indicador de etnicidad. De la región Vaccea a la Arqueología Vaccea (F. Romero Carnicero y C. Sanz Mínguez eds.), Vaccea Monografías 4, Universidad de Valladolid, Valladolid: 293-318.

Arnold, D. E. (2000): Does the standarization of ceramic pastes really mean standarization?. Journal of Archaeological Method and Theory 7: 333-375.

Arnold, D. E. (2006): The Threshold Model for ceramic resources: A refinement. Ceramic studies: papers on the social and cultural significance of ceramics in Europe and Eurasia from prehistoric to historic times (D. Gheorghiu ed.), Archaeopress, Oxford: 3-9.

Balfet, H. (1975) Technologie. Éléments d'ethnologie, vol. 2 (R. Cresswell ed.), Armand Colin, París: 4479.

Barril Vicente, M. (ed.) (2005): El descubrimiento de los vettones: Los materiales del Museo Arqueológico Nacional. Institución Gran Duque de Alba, Ávila. 
Barril Vicente, M. (2007): La denominada vivienda 3 del castro de Las Cogotas. Cuadernos Abulenses 36: 53-103.

Barrio Martín, J. (1987): Los vasos trípodes de la Necrópolis de Las Erijuelas de San Andrés (Cuéllar, Segovia). Apuntes para su estudio. O Arqueólogo Portugués, Série IV (5): 101-123.

Benet, N.; Jiménez, M.C.; Rodríguez, M. B. (1991): Arqueología en Ledesma, una primera aproximación: la excavación en la plaza de San Martín. Del Paleolítico a la Historia (M. Santonja Coord.), Salamanca, Junta de Castilla y León, Museo de Salamanca: 117-136.

Berducou, M. C. (1990): La céramique archéologique. La conservation en archéologie (M.C. Berdocou ed.), Ed. Masson, Paris: 78-119.

Berg, I. (2008): Looking through pots: recent advances in ceramics X-radiography. Journal of Archaeological Science 35: 1177-1188.

Blanco González, A. (2010a): La definición del Hierro Antiguo en el Castro de Las Cogotas (Cardeñosa, Ávila). Consideraciones sobre algunos materiales del Museo Arqueológico Nacional. Complutum, 21(1): 123-143.

Blanco González, A. (2010b): ¿Nuevos hogares para los emigrantes? Casas y paisajes en el debate sobre el límite entre Cogotas I y el primer Hierro en el Valle del Duero. Zephyrus, LXVI: 155-179.

Blanco González, A. (2014): Tracking the social lives of things: biographical insights into Bronze Age pottery in Spain. Antiquity 88(340): 441-455.

Blanco González, A. (2015a): Past fragments: From ceramics to social practices in later prehistoric Iberia. Journal of Social Archaeology 15(3): 342-365.

Blanco González, A. (2015b): Emulación decorativa y cerámicas ancestrales. Posibles fuentes de inspiración de las alfareras meseteñas de la Edad del Bronce. Zephyrus, LXXVI: 39-56,

Blanco-Gonzalez, A. (2015c): Unconventional prehistoric worlds: untangling the Later Bronze Age in Central Iberia. Cambridge Archaeological Journal 25(2): 435-460.

Blasco Bosqued, M. C. (1997): La Edad del Bronce en el interior peninsular. Una aproximación a1 II milenio a.C. en las cuencas de 1os ríos Duero y Tajo. Cuadernos de Prehistoria y Arqueología de la Universidad Autónoma de Madrid 24: 59-100.

Bosch Gimpera, P. (1942): Two Celtic Waves in Spain. Proceedings of the British Academy, XXVI: 1-126.

Bosch Gimpera, P. (1944): El poblamiento antiguo y la formación de los pueblos de España. México.

Bourdieu, P. (1988): La distinción. Criterio y bases sociales del gusto, Ed. Taurus, Madrid.

Bourdieu, P. (1991): El sentido práctico, Ed. Taurus, Madrid.

Bowser, B. (2000): From Pottery to Politics: An Ethnoarchaeological Study of Political Factionalism, Ethnicity and Domestic Pottery Style in the Ecuadorian Amazon. Journal of Archaeological Method and Theory 7(3): 219-248.

Cabré Aguiló, J. (1930): Excavaciones de Las Cogotas (Cardeñosa, Ávila). El Castro. Memorias de la Junta Superior de Excavaciones y Antigüedades 110, Madrid.

Calvo Gálvez, M. (1992): Experimentando con la arcilla y el fuego como en la antigüedad. Tecnología de la cocción cerámica desde la antigüedad hasta nuestros días (Asociación de Ceramología ed.). Asociación de Ceramología, Agost-Alicante: 41-43.

Calvo Trías, M.; Fornés, J.; García Roselló, J.; Juncosa, E. (2004): Propuesta de cadena operativa de la producción cerámica prehistórica a mano. Pyrenae 35(1): 75-92.

Calvo Trías, M.; Gavua, K.; García Roselló, J.; Javaloyas Molina, D.; Albero Santacreu, D. (2011) Social approaches in pottery distribution networks: the case of upper east Ghana. Old Pots Almanac 16(2): 13-17.

Calvo Trías, M.; García Rosselló, J.; Javaloyas Molina, D.; Albero Santacreu, D. (2015): Playing with mud? An ethnoarchaeological approach to children's learning in Kusasi ceramic production. Children, identity and space (M. Sánchez Romero; E. Alarcón García; G. Aranda Jiménez eds.), SSCIP Monograph Series 4, Oxbow, Oxford: 88-104.

Capel, J.; Delgado, R. (1978): Aplicación de métodos ópticos al estudio de cerámicas arqueológicas. Cuadernos de Prehistoria de la Universidad de Granada 3: 343-356.

Castro Martínez, P. V.; Micó Pérez, R.; Encarna Sanahuja, M. E. (1995): Genealogia y cronología de la «Cultura de Cogotas I»: El estilo cerámico y el grupo de Cogotas I en su contexto arqueológico. Boletín del Seminario de Estudios de Arte y Arqueología 61: 51-118.

Castro, P. V.; Lull, V.; Micó, R. (1996): Cronología de la Prehistoria Reciente de la Península Ibérica y Baleares (c. 2800 - 900 cal ANE). BAR International Series 652. Oxford.

Cau, M. A.; Day, P. M.; Baxter, M. J.; Papageorgiou, I.; Iliopoulos, I.; Montana, G. (2004): Exploring Automatic Grouping Procedures in Ceramic Petrology. Journal of Archaeological Science 31: 1325-1338.

Celestino, S.; Rafel, N.; Armada, X.-L. (eds.) (2008): Contacto cultural entre el Mediterráneo y el Atlántico (siglos XII-VIII a.n.e.): la precolonización a debate, Serie Arqueológica 11. Consejo Superior de Investigaciones Científicas, Madrid. 
Coll Conesa, J. (2000): Aspectos de tecnología de producción de la cerámica Ibérica. III Reunió sobre Economía en el Món Iberic (C. Mata Parreño y G. Pérez Jordá eds.). Saguntum-Plav. Extra 3.Universitat de Valencia. Valencia: 191-208.

Costin, C. L. (2000): The use of ethnoarchaeology for the archaeological study of ceramic production. Journal of Archaeological Method and Theory 7-4: 377-403.

Cresswell, R. (1976): Avant-Propos. Techniques et Culture 1: 5-6.

Delibes de Castro, G.; Romero Carnicero, F. (1992): El último milenio a.C. en la Cuenca del Duero. Reflexiones sobre la secuencia cultural. Paleoetnología de la Península Ibérica (M. Almagro-Gorbea; G. Ruiz Zapatero, coords.): Complutum 2-3, Madrid: 233-258.

Delibes de Castro, G.; Romero Carnicero, F. (2011): La plena colonización agraria del Valle Medio del Duero. Aldeas y ciudades en el primer milenio a.C. La Meseta Norte y los orígenes del urbanismo (J. R. Álvarez-Sanchís; A. Jimeno; G. Ruiz Zapatero eds.), Complutum 22(2): 49-94.

Delibes de Castro, G.; Fernández Miranda, M. (1986-1987): Aproximación a la cronología del grupo Cogotas I. Zephyrus, XXXIX- XL: 17-30.

Dietler, M.; Herbich, I. (1998) Habitus, techniques, style: an integrated approach to the social understanding of material culture and boundaries. The Archaeology of Social Boundaries (M. Stark Ed.), Smithsonian Institution Press, Washington: 232-279.

Djorjevic, B. (2013): Pottery Making in Zlakusa. First Ethnoarchaeological Research Project in Serbia. Ethnoarchaeology (F. Lugli; A. Stoppiello; Stefano Biagetti eds.), Current Research and Field Methods, BAR International Series, 2472, Oxford: 49-52.

Dobres, M. A. (2010): Archaeologies of technology, Cambridge Journal of Economics, 34: 103-114.

Dobres, M.; Hoffman, C. (Ed.) (1999): The social Dynamics of Technology. Practice, Politics and World Views, Smithsonian Institution Press, Washington.

Druc, I. (1996): De la Etnografía hacia la Arqueología: Aportes de entrevistas con ceramistas de Ancash (Perú) para la caracterización de la cerámica prehispánica. Bulletin de l'Institut Français d'Etudes Andines, 25(1): 17-41.

Echallier, J. C. (1984): Éléments de technologie céramique et d'analyse des terres cuites archéologiques, Publication de l'Associationpour la Diffusion de l'Archéologie Méridionale, Lambesc.

Eckert, S.L. (2012): Choosing clays and painting pots in the fourteenth-century Zuni region. Potters and Communities of Practice. Glaze Paint and Polychrome Pottery in the American Southwest, a.d. 1250 to 1700 (L.S. Cordel y J.A. Habicht-Mauche eds.), Arizona University Press, Tucson: 55-64.

Eckert, S. L.; Schleher, K. L.; James, W. D. (2015): Communities of identity, communities of practice: Understanding Santa Fe black-on-white pottery in the Española Basin of New Mexico. Journal of Archaeological Science 63: 1-12.

Esparza, A. (1995): La Primera Edad del Hierro. Historia de Zamora I. Delos orígenes al final del Medievo (J. C. Alba López coord.), Zamora: 101-149.

Esparza, A.; Blanco, A. (2008): El solar de Vettonia, antes de los vettones. Arqueología Vettona. La Meseta occidental en la Edad del Hierro (J. Álvarez-Sanchís coord.), Zona Arqueológica 12, Museo Arqueológico Regional, Alcalá de Henares: 79-93.

Fabián García, J.F.; Blanco González, A. (2010): El enterramiento en fosa del cerro de la cabeza (Ávila). La cuestión funeraria en el Bronce Final/Hierro I en el Suroeste de la Meseta Norte. Arqueología, Sociedad, Territorio y Paisaje. Estudios sobre prehistoria reciente, Protohistoria y Transición al mundo romano en Homenaje a $M^{a}$ Dolores Fernández Posse (P. Bueno; A. Gilman; C. Martín Morales; F.J. Sánchez Palencia eds.), Consejo Superior de Investigaciones Científicas, Madrid: 183-194.

Fernández-Posse, M. D. (1998): La investigación protohistórica en La Meseta y Galicia. Arqueología Prehistórica 1. Ed. Síntesis. Madrid.

Freestone, I. (2001): Post-depositional changes in archaeological ceramics and glasses. Handbook of Archaeological Sciences (D.R. Brothwell y A.M. Pollard eds.), John Wiley \& Sons Ltd., New York: 615-625.

Galán Saulnier, C. (1998): Sobre la cronología de Cogotas I..., Cuadernos de Prehistoria y Arqueología de la Universidad Autónoma de Madrid 25: 201-243.

Gandon, E.; Coyle, T.; Bootsma, R. J. (2014): When handicraft experts face novelty: Effects of shape and wheel familiarity on individual and community standardization of ceramic vessels. Journal of Anthropological Archaeology, 35: 289-296.

Ericsson, K.A.; Lehmann, A.C. (1996): Expert and exceptional performance: evidence from maximal adaptation to task constraints. Annual Review of Psychology 47: 273-305.

García Roselló, J. (2008): Etnoarqueología de la producción cerámica: Identidad y territorio en los valles centrales de Chile. Mayurqa 32. Universitat de les Illes Balears. Mallorca.

García Roselló, J. (2009): “Cadena operativa, forma, función y materias primas. Un aporte a través de la producción cerámica del centro de Chile. Relaciones de la Sociedad Argentina de Antropología, XXXIV, pp. 123-148. 
García Roselló, J.; Calvo Trías, M. (2013): Making Pots. El modelado de la cerámica a mano y su potencial interpretativo. B.A.R. International Series, 2540, Oxford.

Gibson, A.; Woods, A. (1990): Prehistoric pottery for the archaeologist. Leicester University Press, Leicester.

Giddens, A (2003): La constitución de la sociedad. Bases para la teoría de la estructuración. Amorrortu editores. Buenos Aires.

Goffer, Z. (2007): Archaeological Chemistry. John Wiley \& Sons ed. Nueva Jersey.

González Tablas, F. J. (1990): La necrópolis de "Los Castillejos" de Sanchorreja. Su contexto histórico. Acta Salmanticensia 69. Ediciones Universidad de Salamanca, Salamanca.

González Tablas, F. J.; Domínguez Calvo, A. (2002): Los Castillejos de Sanchorreja (Ávila): Campañas de 1981. 1982 y 1985. Acta Salmanticensia. Estudios Históricos y Geográficos 117, Ediciones Universidad de Salamanca, Salamanca.

González Ruibal, A. (2005): Etnoarqueología de la cerámica en el oeste de Etiopía. Trabajos de Prehistoria 62(2): 41-66.

González Ruibal, A. (2006): The past is tomorrow. Towards an Archaeology of the Vanishing Present. Norwegian Archaeological Review, 39(2): 110-125.

González Ruibal, A. (en prensa): La lógica social de la cerámica. Un ejemplo etnoarqueológico. Etnoarqueología y Experimentación más allá de la analogía (J. J. Padilla Fernández y E. Alarcón García eds.), Menga.

Gosselain, O. P. (1995): Identités Techniques. Le travail de la poterie au Cameroun méridional, Bruxelles, Tesis doctoral, Universidad Libre de Bruselas.

Gosselain, O. P. (2002): Poteries du Cameroun Meridional. Styles, Techniques et raports a l'identité, CNRS, París.

Gosselain, O. P. (2008): Thoughts and adjustments in the potter's backyard. Breaking the Mould: Challenging the Past through Pottery (I. Berg ed.), BAR International Series 1861, Archaeopress, Oxford: 67-79.

Gosselain, O. P. (2011a): Fine if I do, fine if I don't. Dynamics of technical knowledge in Sub-Saharan Africa. Investigating archaeological cultures (B. W. Roberts y M. Vander Linden eds.), Springer, Nueva York: 211-227.

Gosselain, O. P. (2011b): Pourquoi le decorer? Quelques observations sur le decor ceramique en Afrique. Azania: Archaeological Research in Africa, 46 (1): 3-19.

Graells i Fabregat, R.; Bardelli, G.; Barril Vicente, M. (2014): Ein bronzener stabdreifuss aus Las Cogotas (Cardeñosa, Prov. Ávila), Archäologisches Korrespondenzblatt 44: 59-70.

Hasaki, E. (2012): Craft Apprenticeship in Ancient Greece. Reaching beyond the Masters. Archaeology and apprenticeship. Body knowledge, identity, and communities of practice (W. Wendrich ed.), University Arizona Press, Tucson: 171-202.

Hernando Gonzalo, A. (2012): La fantasía de la individualidad. Sobre la construcción sociohistórica del sujeto moderno, Katz ed., Buenos Aires.

Hernando Gonzalo, A. (2015): ¿Por qué la arqueología oculta la importancia de la comunidad? Trabajos de Prehistoria 72 (1): 22-40.

Hodder, I. (2012:) Entangled. An Archaeology of the Relationships between Humans and Things. WilleyBlackwell, Oxford.

Houbre, A. (2013): La grammaire des decors ceramiques du Neolithique ancien danubien des bassins du Rhin, de la Meuse et de la Seine: Entre norme et transgression. Bulletin de la Société Préhistorique Française, 110 (1): 77-103.

Lemonnier, P. (1992): Elements for an anthropology of technology. Ann Arbor. University of Michigan Press, Michigan.

Lemonnier, P. (2012): Mundane Objects: Materiality and Non-verbal Communication. Left Coast Press, Walnut Creek, California.

Livingstone Smith, A. (2007): Chaîne Operatorie de la Poterie. Réferénces ethnografiques, analices et reconstitution. Musée Royal de l'Afrique Centrale. Tervueren.

Martín Valls, R. (1971): Protohistoria y Romanización de los Vettones. Universidad de Salamanca. Tesis Doctoral Inédita.

Martín Valls, R. (1985): Segunda Edad del Hierro. Las culturas prerromanas. Historia de Castilla y León. I. La Prehistoria del Valle del Duero (J. Valdeón ed.), Ámbito Ediciones S.A., Valladolid: 104-131.

Martín Valls, R. (1986-87): La Segunda Edad del Hierro: consideraciones sobre su periodización. Zephyrus XIL-XL: 59-86.

Martín Valls, R.; Benet, N.; Macarro, C. (1991): Arqueología de Salamanca. Del Paleolítico a la Historia (M. Santonja coord.), Salamanca: Museo de Salamanca: 137-163.

May, P.; Tuckson M. (1982): The Traditional Pottery of Papua New Guinea. Kensington, Bay Books. 
Misiego Tejeda, J.C.; Marcos Contreras, G.J.; Martín Carbajo, M.A.; Sanz García, F.J.; Villanueva Martín, L. A. (2005): Guaya (Berrocalejo de Aragona, Avila): Reconstrucción de la vida y economía de un poblado en los albores de la Edad del Hierro. Bronce final y Edad del Hierro en la Península Ibérica. Encuentro de Jóvenes Investigadores (A. Blanco; C. Cancelo; A. Esparza, eds.), Fundación Duques de Soria. Universidad de Salamanca, Salamanca: 207-228.

Oakley, V.; Jain, K. (2002): Essentials in the care and conservation of historical ceramic objects, Archetype Publications, Londres.

Orton, C.; Tyers, P.; Vince, A. (1997): La cerámica en arqueología. Crítica arqueología. Barcelona.

Palol, P. (1966): Estado actual de la investigación prehistórica y arqueológica en la Meseta castellana. IX Congreso Nacional de Arqueología (Valladolid 1965). Zaragoza: 29-33.

Pelegrin, J. (1985): Réflexions sur le comportement technique, in la signification culturelle des industries lithique. Studia Praehistorica Belgica 4 (M. Otte ed.). British Archaeological Reports, S239. Oxford: 72-91.

Pikirayi, I.; Lindahl, A. (2013): Ceramics, Ethnohistory, and Ethnography: Locating Meaning in Southern African Iron Age Ceramic Assemblages, African Archaeological Review, 30 (4): 455-473.

Ravines, R. (1978): Cerámica actual de Ccaccasari, Huancavelica”. Tecnología cerámica (R. Ravines ed.), Instituto de estudios peruanos, Lima: 447-473.

Rice, P.M. (1987): Pottery Analysis: a Sourcebook, University of Chicago Press, Chicago.

Romero Carnicero, F.; Ramírez Ramírez, M. L. (1996): La Cultura del Soto. Reflexiones sobre los contactos entre el Duero Medio y las tierras del sur peninsular durante la primera Edad del Hierro. Complutum 6 (I): 313-326.

Roux, V. (2009): Technological innovations and developmental trajectories: social factors as evolutionary forces. Innovation in cultural systems. Contributions from evolutionary anthropology (M. O'Brien y S. Shennan eds.), MIT Press, Cambridge: 217-234.

Roux, V. (2016): Des ceramiques et des hommes. Décoder les assemblages archéologiques. Presses Universitaires de Paris Puest, Nanterre.

Ruiz Zapatero, G. (1979): El Roquizal del Rullo: aproximación a la secuencia de los Campos de Urnas del Bajo Aragón. Trabajos de Prehistoria 36: 247-282.

Ruiz Zapatero, G. (2004): La construcción de la 'Cultura de Las Cogotas'. El arqueólogo Juan Cabré (1882-1947). La fotografía como técnica documental (J. Blánquez y B. Rodríguez eds.), Ministerio de Cultura, Madrid: 194-219.

Ruiz Zapatero, G. (2007): Antes del Hierro. Cultura y sociedad en el centro de la Meseta (c. 1200-500 a.C.). Estudios sobre la Edad del Hierro en la Carpetania. Registro arqueológico, secuencia y territorio (A. F. Dávila ed.), Comunidad de Madrid, Madrid: 36-63.

Ruiz Zapatero, G.; Álvarez Sanchís, J.R. (2002): Etnicidad y Arqueología: Tras la identidad de Los Vettones. SPAL 11: 253-275.

Rye, O. S. (1981): Pottery Technology: Principles and Reconstruction. Taraxacum, Washington D.C.

Rye, O. S.; Evans, C. (1976): Traditional pottery techniques of Pakistan, Smithshoniam Contribution Antropology 21, Washington.

Safa Barraza, P. (2002): El concepto de habitus de Pierre Bourdieu y el estudio de las culturas populares en México. Revista Universidad de Guadalajara 24, Universidad de Guadalajara, México.

Sanz Mínguez, C. (1997): Los Vacceos: Cultura y ritos funerarios de un pueblo prerromano del valle medio del Duero. La necrópolis de Las Ruedas, Padilla de Duero (Valladolid), Arqueología en Castilla y León 6. Junta de Castilla y León, Valladolid.

Seco, M.; Treceño, F. (1993): La temprana iberización. de las tierras del sur del Duero a través de la secuencia de La Mota, Medina del Campo (Valladolid). Arqueología Vaccea. Estudios sobre el mundo prerromano en la Cuenca Media del Duero (F. Romero Carnicero; C. Sanz Mínguez; Z. Escudero eds.), Junta de Castilla y León, Valladolid: 133-171.

Sempere, E. (1992): Catalogación de los hornos de España y Portugal. Tecnología de la cocción cerámica desde la antigüedad a nuestros días. Asociación de Ceramología (ed.), Alicante: 155-169.

Schiffer, M.; Skibo, J. (1997): The explanation of artefact variability. American Antiquity 62: 27-50.

Velde, B.; Druc, I. (1999): Archaeological Ceramic Materials: Origin and Utilization. Springer, Berlin.

Van der Leeuw, S. E. (1993): Giving the potter a choice. Conceptual aspects of pottery techniques. Technological choice. Transformations in material cultures sincethe neolitic (P. Lemonnier ed.), Routledge, Londres: 238-288.

Vidal, A.; García Roselló, J. (2009): Dime cómo lo haces: Una visión etnoarqueológica de las estrategias de aprendizaje de alfarería tradicional, Arqueoweb, Revista sobre Arqueología en Internet 12 (1): (visto en http://pendientedemigracion.ucm.es/info/arqueoweb/pdf/12/vidal.pdf).

Wenger, E. (1998): Communities of practices: Learning, Meaning and Identity, Cambridge University Press, Cambridge. 
Woods, A. J. (1985): An introductory note on the use of tangential thin-section for distinguishing between wheel-thrown and coil/ring-built vessels. Bulletin of Experimental Firing Group 5: 100-114. 